\title{
Soybean Sudden Death Syndrome Species Diversity Within North and South America Revealed by Multilocus Genotyping
}

\author{
Kerry O’Donnell, Stacy Sink, María Mercedes Scandiani, Alicia Luque, Analía Colletto, Marisa Biasoli, \\ Lisandro Lenzi, Graciela Salas, Victoria González, Leonardo Daniel Ploper, Norma Formento, \\ Rosanna N. Pioli, Takayuki Aoki, X. B. Yang, and Brice A. J. Sarver
}

First and second authors: Microbial Genomics Research Unit, National Center for Agricultural Utilization Research, U.S. Department of Agriculture, Agriculture Research Service, 1815 North University Street, Peoria IL 61604; third author: Laboratorio Agrícola Río Paraná, San Pedro, Buenos Aires, Argentina; fourth to sixth authors: Centro de Referencia de Micología (CEREMIC), Fac. de Cs. Bioquímicas y Farmacéuticas, UNR, Suipacha 531, 2000, Rosario, Santa Fe; seventh author: Estación Experimental Agropecuaria Marcos Juárez, Instituto Nacional de Tecnología Agropecuaria, (EEA INTA Marcos Juárez), Casilla de Correo 21, 2580 Marcos Juárez, Córdoba; eighth author: Nidera S.A, Catamarca 2597, 4000 San Miguel de Tucumán; ninth and tenth authors: Estación Experimental Agroindustrial "Obispo Colombres", Casilla de Correo 9, 4101, Las Talitas, San Miguel de Tucumán; eleventh author: Estación Experimental Agropecuaria Paraná, Instituto Nacional de Tecnología Agropecuaria, (EEA INTA Paraná), Ruta 11 km 12,5, 3101, Oro Verde, Entre Ríos; twelfth author: Cátedra de Fitopatología, Fac. de Cs. Agrarias-UNR, Campo Experimental Villarino CC 14, 2125 Zavalla, Santa Fe, Argentina; thirteenth author: National Institute of Agrobiological Sciences, Genetic Diversity Department, 2-1-2 Kannondai, Tsukuba, Ibaraki 305-8602, Japan; fourteenth author: Department of Plant Pathology, Iowa State University, Ames, IA 50011; and fifteenth author: Department of Biological Sciences, University of Idaho, Moscow, ID 83844.

Accepted for publication 19 August 2009.

\begin{abstract}
O’Donnell, K., Sink, S., Scandiani, M. M., Luque, A., Colletto, A., Biasoli, M., Lenzi, L., Salas, G., González, V., Ploper, L. D., Formento, N., Pioli, R. N., Aoki, T., Yang, X. B., and Sarver, B. A. J. 2010. Soybean sudden death syndrome species diversity within North and South America revealed by multilocus genotyping. Phytopathology 100:58-71.

Sudden death syndrome (SDS) of soybean has become a serious constraint to the production of this crop in North and South America. Phenotypic and multilocus molecular phylogenetic analyses, as well as pathogenicity experiments, have demonstrated that four morphologically and phylogenetically distinct fusaria can induce soybean SDS. Published molecular diagnostic assays for the detection and identification of these pathogens have reported these pathogens as $F$. solani, $F$. solani f. sp. glycines, or $F$. solani f. sp. phaseoli, primarily because the species limits of these four pathogens were only recently resolved. In light of the recent discovery that soybean SDS and Phaseolus and mung bean root rot (BRR) are caused by four and two distinct species, respectively, multilocus DNA sequence analyses were conducted to assess whether any of the published molecular diagnostic assays were species-specific. Com-
\end{abstract}

ABSTRACT parative DNA sequence analyses of the soybean SDS and BRR pathogens revealed that highly conserved regions of three loci were used in the design of these assays, and therefore none were species-specific based on our current understanding of species limits within the SDS-BRR clade. Prompted by this finding, we developed a high-throughput multilocus genotyping (MLGT) assay which accurately differentiated the soybean SDS and two closely related Phaseolus and mung BRR pathogens based on nucleotide polymorphism within the nuclear ribosomal intergenic spacer region rDNA and two anonymous intergenic regions designated locus 51 and 96. The single-well diagnostic assay, employing flow cytometry and a novel fluorescent microsphere array, was validated by independent multilocus molecular phylogenetic analysis of a 65 isolate design panel. The MLGT assay was used to reproducibly type a total of 262 soybean SDS and 9 BRR pathogens. The validated MLGT array provides a unique molecular diagnostic for the accurate identification and molecular surveillance of these economically important plant pathogens.

Additional keywords: Argentina, Brazil, EF-1 $\alpha$, Glycine max, Phaseolus vulgaris, United States, Vinga radiata.
Sudden death syndrome (SDS) of soybean (Glycine max (L.) Merr.) is responsible for economically devastating reductions in yields of this crop in North and South America (4). Hallmarks of soybean SDS include foliar necrosis and chlorosis, vascular discoloration of roots and stems, root rot, and death (31). Recent systematic and molecular phylogenetic analyses including morphological studies, multilocus DNA sequence data, and pathogenicity assays have shown that soybean SDS is caused by four closely related soilborne fusaria that are morphologically and phylogenetically distinct species (3,4; present study; Fusarium virguli-

Corresponding author: K. O’Donnell; E-mail address: kerry.odonnell@ars.usda.gov

doi:10.1094/PHYTO-100-1-0058

This article is in the public domain and not copyrightable. It may be freely reprinted with customary crediting of the source. The American Phytopathological Society, 2010. forme O’Donnell \& T. Aoki, F. tucumaniae T. Aoki, O'Donnell, Yos. Homma \& Lattanzi, F. brasiliense T. Aoki \& O'Donnell, and an undescribed Fusarium sp.). These studies have also revealed that bean root rot (hereafter referred to as BRR) of dry edible and snap bean (Phaseolus vulgaris L.) and mung bean (Vigna radiata (L.) R. Wilczek) is caused by two other distinct species, F. phaseoli (Burkh.) T. Aoki \& O'Donnell and F. cuneirostrum O'Donnell \& T. Aoki. Results of the present study, based on sampling of additional isolates and loci, have revealed that the single genetically divergent soybean SDS isolate NRRL 31949 from Brazil previously reported as $F$. cuneirostrum (4) represents an unnamed phylogenetically and morphologically distinct species (T. Aoki, unpublished data) herein referred to as Fusarium sp. Symptoms of soybean SDS and BRR include deterioration and discoloration of the main and lateral taproots, leaf chlorosis, defoliation, and death (35). All six species form a genealogically exclusive group within the South American clade (i.e., clade 2) of the $F$. solani species complex (FSSC) (20), suggesting that these root rot 
pathogens evolved from a common ancestor prior to the introduction of soybean to the New World. Although the taxonomic treatments of this genus $(13,19)$ used by most North American plant pathologists follow Snyder and Hansen (39) in recognizing F. solani (Mart.) Appel \& Wollenweber as the only species within the FSSC, molecular phylogenetic analyses indicate that this complex comprises at least 47 phylogenetically distinct species distributed among three strongly supported clades $(20,26,49)$. In addition, the so-called MPI-MPVII mating populations of Nectria haematococca Berk. \& Br. have been shown to represent biologically and phylogenetically distinct species $(18,20)$. Interesting, approximately two-thirds of all fusarial infection of humans and other animals are caused by at least 20 species which are all nested within FSSC clade 3 (26,49), which also includes the model system organism $F$. solani f. sp. pisi, also known as $N$. haematococca MPVI (45).

Because three of the four SDS and the two BRR pathogens were only recently described and given Latin binomials $(3,4)$, these six pathogens have been referred to primarily as $F$. solani $\mathrm{f}$. sp. glycines (31), F. solani f. sp. phaseoli (Burkh.) W. C. Snyder \& H. N. Hansen, or F. solani (Mart.) Sacc. in most studies published to date. Unfortunately, published molecular diagnostic assays for the specific detection of these pathogens $(7,8,14$ 16,22 ) were developed either prior to the application of genealogical concordance phylogenetic species recognition (GCPSR) (40) within the SDS-BRR clade $(3,4)$, or else they did not take into account the species diversity reported in the latter two studies $(8,15)$. In so far as species limits were not considered prior to the development of molecular diagnostic assays for these pathogens, it remains to be established whether any of these assays are species specific.

All polymerase chain reaction (PCR)-based assays published to date for the identification of the SDS and BRR pathogens are limited to uniplex amplifications based on the assumption that the etiological agent was a single species. The current gold standard for identification of the six species within the SDS-BRR clade include time-consuming morphological analyses which require taxonomic expertise (3,4; T. Aoki, unpublished data) and molecular phylogenetic analyses of DNA sequence data $(3,4)$. Laborintensive pathogenicity assays have been used to distinguish soybean SDS and BBR pathogens from one another and from other fusarial pathogens but it is now clear that they do not differentiate the six soybean SDS-BBR clade pathogens (31-33). Application of a biological species concept within this clade has been limited to one of the four South American soybean SDS pathogens, $F$. tucumaniae (6), which is the only species within the SDS-BBR clade with a known teleomorph, in spite of a report to the contrary (1).

Recently, multiplexed single-well DNA sequence-based typing schemes have been developed for Fusarium head blight (FHB) species identification and trichothecene chemotype determination (46) and human pathogenic fusaria (25) utilizing multilocus genotyping (MLGT) of single-nucleotide polymorphisms. Both of these MLGT assays employed Luminex technology and flow cytometry, which take advantage of PCR multiplexing and allelespecific primer extension (ASPE) using microsphere arrays which can accommodate up to 100 different probe primers within a single-well assay. Given this background, the primary objectives of the present study were to (i) further evaluate species limits within the SDS-BRR clade using novel multilocus DNA sequence data; (ii) determine whether published molecular diagnostic assays are specific for any of the SDS and BRR pathogens; (iii) develop and validate a high-throughput, allele-specific microsphere array for the simultaneous detection and identification of all four SDS and both BRR pathogens in a single-well assay using flow cytometry; and (iv) use the MLGT assay to develop a baseline of SDS pathogen diversity in the major soybean-growing regions of Argentina and the United States.

\section{MATERIALS AND METHODS}

Fungal strains and growth conditions. A total of 262 soybean SDS and nine BRR isolates were genotyped in this study. Isolates were analyzed in the following two groups: a panel of 65 soybean SDS and BRR isolates (Table 1) for the design and validation of the MLGT assay (design panel, DP), and an experimental panel (EP) consisting of 205 soybean SDS isolates and one BRR isolate (Table 2). All of the isolates are stored cryogenically in liquid nitrogen vapor at $-175^{\circ} \mathrm{C}$ in the Agricultural Research Service (NRRL) Culture Collection (NCAUR, Peoria, IL) and are available for distribution to promote a greater understanding of their phenotypic and genotypic diversity (10). Yeast-malt broth cultures were used to obtain mycelium for genomic DNA as described previously (21).

Molecular phylogenetics. Genomic DNA isolation, PCR amplification, and multilocus DNA sequencing were conducted as previously described $(6,24)$. A panel of 65 isolates was chosen to represent the phylogenetic diversity of the soybean SDS and BRR pathogens based on previous phylogenetic analyses (4). We identified species-specific DNA polymorphisms within aligned sequences of the nuclear ribosomal intergenic spacer (IGS) rDNA $(2,765$ bp alignment) and anonymous locus 51 (1,530 bp alignment) and 96 (1,520 bp alignment) (6). In addition, partial translation elongation factor $(E F-1 a)$ sequence data were obtained from the same 65 -isolate panel (687 bp alignment). Sequencher (version 4.1.2; Gene Codes, Ann Arbor, MI) was used to edit and align DNA sequences, after which positional homology alignments were improved by manual manipulation of the alignment. Phylogenetic reconstructions employed maximum parsimony (MP) in PAUP (42) and maximum likelihood in GARLI (50) as previously described (26). Clade stability was assessed by 1,000 MP pseudoreplicates of the data (Fig. 1).

Assessment of published SDS and BRR species-specific PCR primers and probes. Several PCR primer pairs and probes have been reported for the specific detection and identification of $F$. solani $\mathrm{f}$. sp. glycines or $F$. solani $\mathrm{f}$. sp. phaseoli $(7,8,14-16,22)$. To assess whether they were specific to one of the four soybean SDS or two BRR pathogens, we PCR amplified and sequenced the three loci employed in the design of the species-specific primers and probes [i.e., nuclear ribosomal internal transcribed spacer region and nuclear large subunit rDNA (22), 5' portion of the $E F$ $1 a$ gene $(7,14)$, and mitochondrial small subunit (mtSSU) ribosomal rDNA $(8,14-16)$ ] in two or more isolates of each soybean SDS and BRR pathogen as previously described (20). DNA sequences were edited and aligned with Sequencher version 4.1.2 and then in silico searches were conducted to ascertain whether the published PCR primers or probes could differentiate the soybean SDS and BRR pathogens. DNA sequences have been deposited in GenBank under accession numbers FJ919398 to FJ919561.

Species-specific probe design. MacClade's data editor (17) was used to design all of the species-specific probes. Sequences of the IGS rDNA partition were used to design species-specific probes for two of the four soybean SDS and the two BRR pathogens; aligned sequences of locus 51 and 96 were each used to design species-specific probes for $F$. tucumaniae and $F$. virguliforme (Fig. 2; Table 3). Each species-specific probe primer ends with a 3 ' single nucleotide diagnostic for one of the six pathogens, as well as species-specific polymorphisms located internally within the probe primers. In addition, one highly conserved oligonucleotide probe was designed as a positive control for PCR amplification and allele-specific primer extension of each locus for all six pathogens within the SDS-BRR clade. A unique 24-bp tag was added to the $5^{\prime}$ end of each primer (Table 3 ), which was obtained from the Luminex Corporation website (http://www. luminexcorp.com/).

Multiplex amplification for MLGT assay. We obtained IGS rDNA and locus 51 and 96 templates for the multiplex primer 
extension by co-amplifying portions of these genomic regions using PCR primers NL11 $\times$ CNS1, 51-1 × 51-2, and 96-1a $\times$ 96-2a, respectively (6). Multiplex PCR amplifications were performed in a total volume of $40-\mu$ l following the manufacturer's instructions, and included 1× High Fidelity PCR buffer (Invitrogen Life Technologies, Carlsbad, CA), $1.25 \mathrm{mM} \mathrm{MgSO}_{4}, 0.2 \mathrm{mM}$ of each deoxynucleoside triphosphate, 10 pmol of each primer, $0.5 \mathrm{U}$ of Platinum Taq DNA Polymerase High Fidelity, and

TABLE 1. Design panel of sudden death syndrome and bean root rot fusaria used in the validation of the allele-specific genotyping assay

\begin{tabular}{|c|c|c|c|c|c|c|}
\hline $\mathrm{NRRL}^{\mathrm{a}}$ & Species & Equivalent no. ${ }^{b}$ & Host & Origin & Index of discrimination $^{c}$ & $\begin{array}{c}\text { Year } \\
\text { isolated }\end{array}$ \\
\hline 22158 & Fusarium cuneirostrum & ATCC 60860 & Phaseolus vulgaris & USA, New York & $8(\mathrm{CU}-\mathrm{a})$ & Unknown \\
\hline 22275 & Fusarium cuneirostrum & $\begin{array}{l}\text { Matuo SUF } 386=\text { MAFF } \\
239036\end{array}$ & Phaseolus vulgaris & $\begin{array}{l}\text { Japan, Hokkaido, } \\
\text { Sapporo }\end{array}$ & $10(\mathrm{CU}-\mathrm{a})$ & 1955 \\
\hline 22276 & Fusarium phaseoli & $\begin{array}{c}\text { van Etten T-162 = MAFF } \\
238544=\text { CCC 189-05 }\end{array}$ & Phaseolus vulgaris & USA & 18 (PH-a), 4 (PH-b) & Unknown \\
\hline 22292 & Fusarium virguliforme & Gray Mont-1 & Glycine $\max$ & USA, Illinois & $\begin{array}{l}21 \text { (96-VI-1), } 24 \text { (51-VI-1), } \\
44 \text { (51-VI-2) }\end{array}$ & 1991 \\
\hline 22411 & Fusarium phaseoli & $\begin{array}{l}\text { ATCC } 38466=\mathrm{CCC} \\
\quad 100-03\end{array}$ & Phaseolus vulgaris & USA, California & 10 (PH-a), 4 (PH-b) & Unknown \\
\hline 22678 & Fusarium brasiliense & $\begin{array}{l}\text { FRC S-712 = MAFF } \\
\quad 239039\end{array}$ & Glycine max & USA, California & $21(B-a), 6(B-b)$ & 1993 \\
\hline 22743 & Fusarium brasiliense & $\begin{array}{l}\text { BBA } 68441=\text { MAFF } \\
239041\end{array}$ & Glycine $\max$ & $\begin{array}{l}\text { Brazil, Distrito } \\
\text { Federal, Brasilia }\end{array}$ & $51(\mathrm{~B}-\mathrm{a}), 7$ (B-b) & 1992 \\
\hline 22823 & Fusarium virguliforme & Abney IN-11-60-4 & Glycine $\max$ & USA, Indiana & $\begin{array}{l}21 \text { (96-VI-1), } 24 \text { (51-VI-1), } \\
\quad 41 \text { (51-VI-2) }\end{array}$ & Unknown \\
\hline 22825 & Fusarium virguliforme & Abney IN-F2X-11A & Glycine max & USA, Indiana & $\begin{array}{l}22 \text { (96-VI-1), } 22 \text { (51-VI-1), } \\
43 \text { (51-VI-2) }\end{array}$ & Unknown \\
\hline 31041 & Fusarium virguliforme $(\mathrm{T})$ & Li \#95 & Glycine max & USA, Illinois & $\begin{array}{l}20 \text { (96-VI-1), } 21 \text { (51-VI-1) } \\
\quad 38 \text { (51-VI- } 2)\end{array}$ & 1998 \\
\hline 31085 & Fusarium tucumaniae & $\begin{array}{l}\text { Homma MJ-123 = MAFF } \\
238405\end{array}$ & Glycine $\max$ & $\begin{array}{l}\text { Argentina, Córdoba, } \\
\text { General Roca }\end{array}$ & $9(\mathrm{TU}-\mathrm{a}), 13$ (TU-c) & 2000 \\
\hline 31096 & Fusarium tucumaniae $(\mathrm{T})$ & MAFF 238418 & Glycine $\max$ & $\begin{array}{l}\text { Argentina, Tucumán, } \\
\text { San Agustín }\end{array}$ & 10 (TU-a), 13 (TU-c) & 2001 \\
\hline 31100 & Fusarium tucumaniae & MAFF 238411 & Glycine $\max$ & $\begin{array}{l}\text { Argentina, Santa Fe, } \\
\text { Las Rosas }\end{array}$ & 10 (TU-a), 13 (TU-c) & 2001 \\
\hline 31104 & Fusarium cuneirostrum & MAFF 305607 & Phaseolus vulgaris & Japan & $10(C U-a)$ & Unknown \\
\hline 31156 & Fusarium phaseoli & $\begin{array}{l}\text { FRC S }-1550=\text { MAFF } \\
238550=\text { CCC 190-05 }\end{array}$ & Phaseolus vulgaris & USA, Michigan & 14 (PH-a), 4 (PH-b) & Unknown \\
\hline 31157 & Fusarium cuneirostrum $(\mathrm{T})$ & $\begin{array}{l}\text { FRC S-1551 = MAFF } \\
239038=\text { CCC 192-05 }\end{array}$ & Phaseolus vulgaris & USA, Michigan & $5(\mathrm{CU}-\mathrm{a})$ & 1992 \\
\hline 31756 & Fusarium brasiliense & $\begin{array}{r}\text { Yorinori SDS }-1=\text { MAFF } \\
239043=\text { CCC 124-02 }\end{array}$ & Glycine $\max$ & $\begin{array}{l}\text { Brazil, Distrito } \\
\text { Federal, Brasilia }\end{array}$ & 17 (B-a), 5 (B-b) & 1992 \\
\hline 31757 & Fusarium brasiliense $(\mathrm{T})$ & $\begin{array}{l}\text { Yorinori SDS-5 = MAFF } \\
239050\end{array}$ & Glycine max & $\begin{array}{l}\text { Brazil, Distrito } \\
\text { Federal, Brasilia }\end{array}$ & 16 (B-a), 5 (B-b) & 1992 \\
\hline 31762 & Fusarium brasiliense & $\begin{array}{l}\text { Yorinori 06/98 = MAFF } \\
239051=\text { CCC 193-05 }\end{array}$ & Glycine max & $\begin{array}{l}\text { Brazil, Paraná, Campo } \\
\text { Mourão }\end{array}$ & 21 (B-a), 6 (B-b) & 1998 \\
\hline 31776 & Fusarium tucumaniae & $\begin{array}{l}\text { Yorinori } 33 / 00=\text { MAFF } \\
239054\end{array}$ & Glycine $\max$ & $\begin{array}{l}\text { Brazil, Rio Grande do } \\
\quad \text { Sul, Tapera }\end{array}$ & 9 (TU-a), 12 (TU-c) & 2000 \\
\hline 31777 & Fusarium tucumaniae & $\begin{array}{l}\text { Yorinori 34/00 = MAFF } \\
239045\end{array}$ & Glycine $\max$ & $\begin{array}{l}\text { Brazil, Rio Grande do } \\
\text { Sul, Vila Maria }\end{array}$ & 9 (TU-a), 13 (TU-c) & 2000 \\
\hline 31778 & Fusarium tucumaniae & $\begin{array}{l}\text { Yorinori } 35 / 00=\text { MAFF } \\
239046\end{array}$ & Glycine $\max$ & $\begin{array}{l}\text { Brazil, Rio Grande do } \\
\quad \text { Sul, Sarandi }\end{array}$ & $8(\mathrm{TU}-\mathrm{a}), 12$ (TU-c) & 2000 \\
\hline 31779 & Fusarium brasiliense & $\begin{array}{r}\text { Yorinori } 36 / 00=\text { MAFF } \\
239047=\text { CCC 194-05 }\end{array}$ & Glycine $\max$ & $\begin{array}{l}\text { Brazil, Rio Grande do } \\
\text { Sul, Nonai }\end{array}$ & $11(\mathrm{~B}-\mathrm{a}), 3(\mathrm{~B}-\mathrm{b})$ & 2000 \\
\hline 31781 & Fusarium tucumaniae & Yorinori $41 / 00=$ MAFF & Glycine $\max$ & Argentina, Tucumán & 7 (TU-a), 15 (TU-c) & Unknown \\
\hline 31793 & Fusarium tucumaniae & $\begin{array}{l}\text { Yorinori } 71 / 00=\text { MAFF } \\
239048\end{array}$ & Glycine $\max$ & $\begin{array}{l}\text { Brazil, Minas Gerais, } \\
\text { Nova Ponte }\end{array}$ & 8 (TU-a), 12 (TU-c) & 2001 \\
\hline 31949 & Fusarium sp. (T) & $\begin{array}{l}\text { Yorinori } 01 / 00=\text { MAFF } \\
239052=\text { CCC 198-05 }\end{array}$ & Glycine $\max$ & $\begin{array}{l}\text { Brazil, Goiás, } \\
\text { Cristalina }\end{array}$ & 43 (CR-a), 15 (CR-b) & 2000 \\
\hline 31950 & Fusarium tucumaniae & Yorinori $07 / 00$ & Glycine $\max$ & $\begin{array}{l}\text { Brazil, Paraná, Ponta } \\
\text { Grossa }\end{array}$ & 8 (TU-a), 14 (TU-c) & 2000 \\
\hline 32392 & Fusarium virguliforme & NSPCC i101 & Glycine $\max$ & USA, Wisconsin & $\begin{array}{l}22 \text { (96-VI-1), } 21 \text { (51-VI-1), } \\
40 \text { (51-VI-2) }\end{array}$ & 1998 \\
\hline 32458 & Fusarium virguliforme & Fsg-ISU 1 & Glycine max & USA, Iowa-Boone & $\begin{array}{l}22 \text { (96-VI-1), } 21 \text { (51-VI-1), } \\
41 \text { (51-VI-2) }\end{array}$ & 1993 \\
\hline 32459 & Fusarium virguliforme & Fsg-ISU 2 & Glycine max & USA, Iowa-Cerro & $\begin{array}{l}23 \text { (96-VI-1), } 22 \text { (51-VI-1) } \\
\quad 43 \text { (51-VI-2) }\end{array}$ & 2000 \\
\hline 32462 & Fusarium virguliforme & Fsg-ISU 5 & Glycine $\max$ & $\begin{array}{l}\text { USA, Iowa- } \\
\text { Chickasaw }\end{array}$ & $\begin{array}{l}22 \text { (96-VI-1), } 19 \text { (51-VI-1), } \\
\quad 39 \text { (51-VI-2) }\end{array}$ & 2000 \\
\hline \multicolumn{7}{|c|}{ (Continued on next page) } \\
\hline
\end{tabular}

a NRRL = Agriculture Research Service Culture Collection, National Center for Agricultural Utilization Research, USDA-ARS, Peoria, IL.

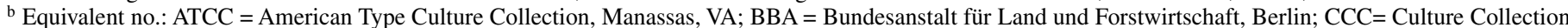
of CEREMIC (Centro de Referencia de Micología), Fac. de Cs. Bioquímicas y Farmacéuticas, UNR, Rosario, Argentina; FRC = Fusarium Research Center, Department of Plant Pathology, Pennsylvania State University, University Park, PA; Fsg-ISU = Department of Plant Pathology, Iowa State University, Ames, IA; MAFF = NIAS Genbank-Microorganisms Section, National Institute of Agrobiological Sciences (NIAS), 2-1-2 Kannondai, Tsukuba, Ibaraki 305-8602, Japan; NSPCC $=$ National Soybean Pathogen Culture Collection, ARS-USDA, Urbana, IL.

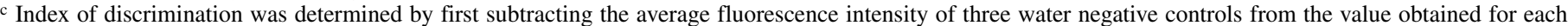
DNA sample, and then dividing the minimum fluorescence intensity by the maximum nontarget fluorescence intensity. Species-specific probe primers are indicated in parentheses (Table 3 provides probes used in the assay). 
approximately $10 \mathrm{ng}$ of genomic DNA of one of the SDS or BRR pathogens. PCRs employed an initial denaturation of $90 \mathrm{~s}$ at $94^{\circ} \mathrm{C}, 40$ cycles for $30 \mathrm{~s}$ at $94^{\circ} \mathrm{C}, 30 \mathrm{~s}$ at $55^{\circ} \mathrm{C}$, and $210 \mathrm{~s}$ at $68^{\circ} \mathrm{C}$, followed by a $4^{\circ} \mathrm{C}$ soak. Amplicons were purified using Montage
$\mathrm{PCR}_{96}$ Cleanup filter plates (Millipore, Billerica, MA) and stored at $-20^{\circ} \mathrm{C}$ prior to being used as template for the ASPE reactions.

MLGT assay primer extension, hybridization and detection. Purified IGS rDNA and locus 51 and 96 templates were TABLE 1. (Continued from preceeding page)

\begin{tabular}{|c|c|c|c|c|c|c|}
\hline NRRL $^{\mathrm{a}}$ & Species & Equivalent no. ${ }^{\mathrm{b}}$ & Host & Origin & Index of discrimination $^{c}$ & $\begin{array}{l}\text { Year } \\
\text { isolated }\end{array}$ \\
\hline 32466 & Fusarium virguliforme & Fsg-ISU 9 & Glycine max & USA, Iowa-Clinton & $\begin{array}{l}22 \text { (96-VI-1), } 20 \text { (51-VI-1), } \\
\quad 41 \text { (51-VI-2) }\end{array}$ & 1995 \\
\hline 32469 & Fusarium virguliforme & Fsg-ISU 12 & Glycine max & USA, Iowa-Greene & $\begin{array}{l}23 \text { (96-VI-1), } 21 \text { (51-VI-1), } \\
41 \text { (51-VI-2) }\end{array}$ & 1996 \\
\hline 32470 & Fusarium virguliforme & Fsg-ISU 13 & Glycine $\max$ & USA, Iowa-Henry & $\begin{array}{l}10 \text { (96-VI-1), } 10 \text { (51-VI-1), } \\
22 \text { (51-VI-2) }\end{array}$ & 1994 \\
\hline 32472 & Fusarium virguliforme & Fsg-ISU 15 & Glycine $\max$ & USA, Iowa-Jasper & $\begin{array}{l}21 \text { (96-VI-1), } 21 \text { (51-VI-1), } \\
\quad 39 \text { (51-VI-2) }\end{array}$ & 1994 \\
\hline 32473 & Fusarium virguliforme & Fsg-ISU 16 & Glycine $\max$ & USA, Iowa-Johnson & $\begin{array}{l}22 \text { (96-VI-1), } 22 \text { (51-VI-1), } \\
\quad 40 \text { (51-VI-2) }\end{array}$ & 1994 \\
\hline 32474 & Fusarium virguliforme & Fsg-ISU 17 & Glycine max & USA, Iowa-Latham & $\begin{array}{l}22 \text { (96-VI-1), } 19 \text { (51-VI-1), } \\
37 \text { (51-VI-2) }\end{array}$ & Unknown \\
\hline 32475 & Fusarium virguliforme & Fsg-ISU 18 & Glycine max & USA, Missouri-Mont & $\begin{array}{l}23 \text { (96-VI-1), } 22 \text { (51-VI-1), } \\
39 \text { (51-VI-2) }\end{array}$ & Prior 1993 \\
\hline 32477 & Fusarium virguliforme & Fsg-ISU 20 & Glycine $\max$ & USA, Missouri-Mont & $\begin{array}{l}22 \text { (96-VI-1), } 25 \text { (51-VI-1), } \\
50 \text { (51-VI-2) }\end{array}$ & Prior 1993 \\
\hline 32478 & Fusarium virguliforme & Fsg-ISU 21 & Glycine $\max$ & USA, Iowa-Scott & $\begin{array}{l}24 \text { (96-VI-1), } 22 \text { (51-VI-1) } \\
\quad 42 \text { (51-VI-2) }\end{array}$ & 1993 \\
\hline 32481 & Fusarium virguliforme & Fsg-ISU 24 & Glycine $\max$ & USA, Iowa-Worth & $\begin{array}{l}23 \text { (96-VI-1), } 20 \text { (51-VI-1), } \\
\quad 40 \text { (51-VI-2) }\end{array}$ & 1995 \\
\hline 34436 & Fusarium virguliforme & FRC S-1281L = Gray 269 & Glycine $\max$ & USA, Arkansas & $\begin{array}{l}10 \text { (96-VI-1), } 10 \text { (51-VI-1), } \\
21 \text { (51-VI-2) }\end{array}$ & Prior 1993 \\
\hline 34437 & Fusarium virguliforme & $\begin{array}{l}\text { FRC S-1286L = Gray } \\
\quad \text { L145 }\end{array}$ & Glycine $\max$ & USA, Arkansas & $\begin{array}{l}23 \text { (96-VI-1), } 25 \text { (51-VI-1), } \\
\quad 42 \text { (51-VI-2) }\end{array}$ & Prior 1993 \\
\hline 34546 & Fusarium tucumaniae & CCC $125-02$ & Glycine max & $\begin{array}{l}\text { Argentina, Buenos } \\
\text { Aires, Arrecifes }\end{array}$ & 10 (TU-a), 14 (TU-c) & 2000 \\
\hline 34547 & Fusarium tucumaniae & CCC 126-02 & Glycine $\max$ & $\begin{array}{l}\text { Argentina, Santa Fe, } \\
\text { Las Parejas }\end{array}$ & 14 (TU-a), 16 (TU-c) & 2001 \\
\hline 34549 & Fusarium tucumaniae & CCC 129-02 & Glycine $\max$ & $\begin{array}{l}\text { Argentina, Buenos } \\
\text { Aires, PérezMillán }\end{array}$ & 14 (TU-a), 18 (TU-c) & 2000 \\
\hline 34550 & Fusarium tucumaniae & CCC 128-02 & Glycine $\max$ & $\begin{array}{l}\text { Argentina, Santa Fe, } \\
\text { Pujato }\end{array}$ & 13 (TU-a), 17 (TU-c) & 2000 \\
\hline 34551 & Fusarium virguliforme & CCC 101-03 & Glycine $\max$ & $\begin{array}{l}\text { Argentina, Buenos } \\
\text { Aires, San Pedro }\end{array}$ & $\begin{array}{l}19 \text { (96-VI-1), } 23 \text { (51-VI-1), } \\
37 \text { (51-VI-2) }\end{array}$ & 2002 \\
\hline 34552 & Fusarium virguliforme & CCC 102-03 & Glycine $\max$ & $\begin{array}{l}\text { Argentina, Santa Fe, } \\
\text { Serodino }\end{array}$ & $\begin{array}{l}18 \text { (96-VI-1), } 25 \text { (51-VI-1), } \\
\quad 38 \text { (51-VI-2) }\end{array}$ & 2002 \\
\hline 34553 & Fusarium virguliforme & CCC 103-03 & Glycine max & $\begin{array}{l}\text { Argentina, Santa Fe, } \\
\text { Serodino }\end{array}$ & $\begin{array}{l}16 \text { (96-VI-1), } 21 \text { (51-VI-1), } \\
\quad 34 \text { (51-VI-2) }\end{array}$ & 2002 \\
\hline 34938 & Fusarium brasiliense & CCC 195-05 & Glycine $\max$ & $\begin{array}{l}\text { Brasil, Rio Grande do } \\
\text { Sul, Passo Fundo }\end{array}$ & 30 (B-a), 7 (B-b) & 2003 \\
\hline 34939 & Fusarium tucumaniae & BRS 137 & Glycine $\max$ & $\begin{array}{l}\text { Brasil, Rio Grande do } \\
\text { Sul, Passo Fundo }\end{array}$ & 13 (TU-a), 15 (TU-c) & 2003 \\
\hline 36023 & Fusarium cuneirostrum & CCC 196-05 & Vigna radiata & $\begin{array}{l}\text { Canada, Ontario, } \\
\text { Ridgetown }\end{array}$ & $8(\mathrm{CU}-\mathrm{a})$ & 1996 \\
\hline 36605 & Fusarium virguliforme & CCC 156-05 & Soil & $\begin{array}{l}\text { Argentina, Buenos } \\
\text { Aires, Pergamino }\end{array}$ & $\begin{array}{l}17 \text { (96-VI-1), } 23 \text { (51-VI-1), } \\
\quad 35 \text { (51-VI-2) }\end{array}$ & 1999 \\
\hline 36606 & Fusarium virguliforme & RupeArg 1.2 & Soil & $\begin{array}{l}\text { Argentina, Buenos } \\
\text { Aires, Pergamino }\end{array}$ & $\begin{array}{l}17 \text { (96-VI-1), } 20 \text { (51-VI-1), } \\
\quad 32 \text { (51-VI-2) }\end{array}$ & 1999 \\
\hline 36607 & Fusarium virguliforme & CCC 158-05 & Soil & $\begin{array}{l}\text { Argentina, Buenos } \\
\text { Aires, Pergamino }\end{array}$ & $\begin{array}{l}16 \text { (96-VI-1), } 20 \text { (51-VI-1), } \\
\quad 34 \text { (51-VI-2) }\end{array}$ & 1999 \\
\hline 36610 & Fusarium virguliforme & CCC 159-05 & Soil & $\begin{array}{l}\text { Argentina, Buenos } \\
\text { Aires, Pergamino }\end{array}$ & $\begin{array}{l}18 \text { (96-VI-1), } 21 \text { (51-VI-1), } \\
32 \text { (51-VI-2) }\end{array}$ & 1999 \\
\hline 36611 & Fusarium virguliforme & CCC $160-05$ & Soil & $\begin{array}{l}\text { Argentina, Buenos } \\
\text { Aires, Pergamino }\end{array}$ & $\begin{array}{l}17 \text { (96-VI-1), } 23 \text { (51-VI-1), } \\
\quad 35 \text { (51-VI-2) }\end{array}$ & 1999 \\
\hline 36877 & Fusarium sp. & CCC 142-05 & Glycine $\max$ & $\begin{array}{l}\text { Argentina, Santa Fe, } \\
\text { Zavalla }\end{array}$ & 36 (CR-a), 14 (CR-b) & 2004 \\
\hline 36878 & Fusarium tucumaniae & CCC 209-05 & Glycine max & $\begin{array}{l}\text { Argentina, Santa Fe, } \\
\text { Zavalla }\end{array}$ & 12 (TU-a), 14 (TU-c) & 2004 \\
\hline 36880 & Fusarium tucumaniae & CCC 211-05 & Glycine $\max$ & $\begin{array}{l}\text { Argentina, Santa Fe, } \\
\text { Los Molinos }\end{array}$ & 13 (TU-a), 18 (TU-c) & 2004 \\
\hline 36896 & Fusarium virguliforme & CCC 216-05 & Glycine max & $\begin{array}{l}\text { Argentina, Santa Fe, } \\
\text { Los Molinos }\end{array}$ & $\begin{array}{l}17 \text { (96-VI-1), } 22 \text { (51-VI-1), } \\
\quad 35 \text { (51-VI-2) }\end{array}$ & 2004 \\
\hline 36897 & Fusarium virguliforme & CCC 217-05 & Glycine max & $\begin{array}{l}\text { Argentina, Santa Fe, } \\
\text { Los Molinos }\end{array}$ & $\begin{array}{l}17 \text { (96-VI-1), } 21 \text { (51-VI-1), } \\
\quad 35 \text { (51-VI-2) }\end{array}$ & 2004 \\
\hline 36899 & Fusarium virguliforme & CCC 219-05 & Glycine max & $\begin{array}{l}\text { Argentina, Santa Fe, } \\
\text { Los Molinos }\end{array}$ & $\begin{array}{l}17 \text { (96-VI-1), } 19 \text { (51-VI-1), } \\
\quad 32 \text { (51-VI-2) }\end{array}$ & 2004 \\
\hline 36900 & Fusarium virguliforme & CCC 220-05 & Glycine $\max$ & $\begin{array}{l}\text { Argentina, Santa Fe, } \\
\text { Los Molinos }\end{array}$ & $\begin{array}{l}14 \text { (96-VI-1), } 16 \text { (51-VI-1), } \\
\quad 30 \text { (51-VI-2) }\end{array}$ & 2004 \\
\hline
\end{tabular}


TABLE 2. Experimental panel of sudden death syndrome and bean root rot fusaria analyzed by allele-specific genotyping

\begin{tabular}{|c|c|c|c|c|c|c|}
\hline NRRL $^{\mathrm{a}}$ & Species & Equivalent no. ${ }^{\mathrm{b}}$ & Host & Origin & $\begin{array}{c}\text { Index of } \\
\text { discrimination }\end{array}$ & $\begin{array}{l}\text { Year } \\
\text { isolated }\end{array}$ \\
\hline 22411 & Fusarium phaseoli & ATCC $38466=$ CCC 100-03 & $\begin{array}{l}\text { Phaseolus } \\
\text { vulgaris }\end{array}$ & USA, California & 10 (PH-a), 4 (PH-b) & Unknown \\
\hline 22489 & Fusarium virguliforme & K. Roy FSA Poinset = T-501 & Glycine max & USA & $\begin{array}{l}22 \text { (96-VI-1), } 23 \text { (51-VI-1) } \\
43 \text { (51-VI-2) }\end{array}$ & Unknown \\
\hline 22490 & Fusarium virguliforme & K. Roy FSA Lu = T-502 & Glycine $\max$ & USA & $\begin{array}{l}24 \text { (96-VI-1), } 21 \text { (51-VI-1) } \\
\quad 42 \text { (51-VI-2) }\end{array}$ & Unknown \\
\hline 22743 & Fusarium brasiliense & BBA 68441 = MAFF 239041 & Glycine $\max$ & Brazil, DF, Brasilia & 51 (B-a), 7 (B-b) & 1992 \\
\hline 22744 & Fusarium brasiliense & BBA $68442=$ MAFF 239050 & Glycine $\max$ & Brazil, DF, Brasilia & 30 (B-a), 8 (B-b) & 1992 \\
\hline 31039 & Fusarium virguliforme & $\mathrm{Li} \# 45$ & Glycine max & USA, Illinois & $\begin{array}{l}18 \text { (96-VI-1), } 17 \text { (51-VI-1), } \\
34 \text { (51-VI-2) }\end{array}$ & 1994 \\
\hline 31040 & Fusarium virguliforme & $\mathrm{Li} \# 52$ & Glycine $\max$ & USA, Illinois & $\begin{array}{l}19 \text { (96-VI-1), } 19 \text { (51-VI-1), } \\
37 \text { (51-VI-2) }\end{array}$ & Unknown \\
\hline 31086 & Fusarium tucumaniae & $\begin{array}{c}\text { Homma MJ-123 = MAFF } \\
238406=\text { CCC } 175-05\end{array}$ & Glycine $\max$ & $\begin{array}{l}\text { Argentina, General Roca, } \\
\text { Córdoba }\end{array}$ & 6 (TU-a), 11 (TU-C) & 2000 \\
\hline 31087 & Fusarium tucumaniae & MAFF $238407=$ CCC 176-05 & Glycine $\max$ & $\begin{array}{l}\text { Argentina, General Roca, } \\
\text { Córdoba }\end{array}$ & $6(\mathrm{TU}-\mathrm{a}), 9$ (TU-C) & 2001 \\
\hline 31088 & Fusarium tucumaniae & MAFF 238408 & Glycine max & $\begin{array}{l}\text { Argentina, General Roca, } \\
\text { Córdoba }\end{array}$ & 9 (TU-a), 11 (TU-C) & 2001 \\
\hline 31089 & Fusarium tucumaniae & MAFF 238410 & Glycine max & $\begin{array}{l}\text { Argentina, General Roca, } \\
\text { Córdoba }\end{array}$ & 6 (TU-a), 9 (TU-C) & 2001 \\
\hline 31090 & Fusarium tucumaniae & MAFF 238412 & Glycine max & Argentina, Cordoba & $8(T U-a)$ & 2001 \\
\hline 31091 & Fusarium tucumaniae & MAFF $238413=$ CCC 177-05 & Glycine $\max$ & $\begin{array}{l}\text { Argentina, Tucumán, San } \\
\text { Agustin }\end{array}$ & 8 (TU-a), 13 (TU-C) & 2001 \\
\hline 31092 & Fusarium tucumaniae & MAFF 238414 & Glycine $\max$ & $\begin{array}{l}\text { Argentina, Tucumán, San } \\
\text { Agustin }\end{array}$ & 9 (TU-a), 16 (TU-C) & 2001 \\
\hline 31093 & Fusarium tucumaniae & MAFF 238415 & Glycine $\max$ & Argentina, Tucumán & 9 (TU-a) & 2001 \\
\hline 31094 & Fusarium tucumaniae & MAFF $238416=$ CCC 178-05 & Glycine max & $\begin{array}{l}\text { Argentina, Tucumán, San } \\
\text { Agustin }\end{array}$ & 9 (TU-a), 11 (TU-C) & 2001 \\
\hline 31095 & Fusarium tucumaniae & MAFF 238417 = CCC 179-05 & Glycine $\max$ & $\begin{array}{l}\text { Argentina, Tucumán, San } \\
\text { Agustin }\end{array}$ & 9 (TU-a), 12 (TU-C) & 2001 \\
\hline 31097 & Fusarium tucumaniae & MAFF $238419=$ CCC 180-05 & Glycine $\max$ & $\begin{array}{l}\text { Argentina, Tucumán, San } \\
\text { Agustin }\end{array}$ & 9 (TU-a), 14 (TU-C) & 2001 \\
\hline 31098 & Fusarium tucumaniae & MAFF $238420=$ CCC 181-05 & Glycine max & $\begin{array}{l}\text { Argentina, Tucumán, San } \\
\text { Agustin }\end{array}$ & 8 (TU-a), 11 (TU-C) & 2001 \\
\hline 31099 & Fusarium tucumaniae & MAFF 238409 & Glycine $\max$ & $\begin{array}{l}\text { Argentina, General Roca, } \\
\text { Córdoba }\end{array}$ & 9 (TU-a), 13 (TU-C) & 2001 \\
\hline 31773 & Fusarium tucumaniae & Yorinori 15/11= MAFF 239044 & Glycine $\max$ & Brazil, PR, Ponta Grossa & 9 (TU-a), 13 (TU-C) & 2000 \\
\hline 31796 & Fusarium tucumaniae & Yorinori 86/01 = MAFF 239049 & Glycine $\max$ & Brazil, PR, Ponta Grossa & 7 (TU-a), 8 (TU-C) & 1986 \\
\hline 32389 & Fusarium virguliforme & NSPCC i26 & Glycine max & USA, Illinois & $\begin{array}{l}21 \text { (96-VI-1), } 22 \text { (51-VI-1), } \\
\quad 38 \text { (51-VI-2) }\end{array}$ & Unknown \\
\hline 32390 & Fusarium virguliforme & NSPCC i52 & Glycine $\max$ & USA, Illinois & $\begin{array}{l}21 \text { (96-VI-1), } 19 \text { (51-VI-1), } \\
\quad 38 \text { (51-VI-2) }\end{array}$ & 1996 \\
\hline 32391 & Fusarium virguliforme & NSPCC i57 & Glycine $\max$ & USA, Arkansas & $\begin{array}{l}21 \text { (96-VI-1), } 19 \text { (51-VI-1), } \\
38 \text { (51-VI-2) }\end{array}$ & 1996 \\
\hline 32393 & Fusarium virguliforme & NSPCC i159 & Glycine max & USA, Illinois & $\begin{array}{l}23 \text { (96-VI-1), } 21 \text { (51-VI-1) } \\
\quad 42 \text { (51-VI- } 2)\end{array}$ & 1999 \\
\hline 32394 & Fusarium virguliforme & NSPCC i170 & Glycine $\max$ & USA, Illinois & $\begin{array}{l}22 \text { (96-VI-1), } 20 \text { (51-VI-1), } \\
\quad 39 \text { (51-VI-2) }\end{array}$ & 1999 \\
\hline 32395 & Fusarium virguliforme & NSPCC i171 & Glycine max & USA, Illinois & $\begin{array}{l}20 \text { (96-VI-1), } 18 \text { (51-VI-1), } \\
34 \text { (51-VI-2) }\end{array}$ & 1999 \\
\hline 32396 & Fusarium virguliforme & NSPCC i173 & Glycine max & USA, Illinois & $\begin{array}{l}19 \text { (96-VI-1), } 19 \text { (51-VI-1), } \\
\quad 38 \text { (51-VI-2) }\end{array}$ & 1999 \\
\hline 32397 & Fusarium virguliforme & NSPCC i300 & Glycine $\max$ & USA, Illinois & $\begin{array}{l}22 \text { (96-VI-1), } 20 \text { (51-VI-1), } \\
\quad 41 \text { (51-VI-2) }\end{array}$ & 1991 \\
\hline 32398 & Fusarium virguliforme & NSPCC i501 & Glycine $\max$ & USA, Illinois & $\begin{array}{l}22 \text { (96-VI-1), } 21 \text { (51-VI-1), } \\
\quad 41 \text { (51-VI-2) }\end{array}$ & 2001 \\
\hline 32460 & Fusarium virguliforme & Fsg-ISU 3 & Glycine max & USA, Iowa-Cerro & $\begin{array}{l}21 \text { (96-VI-1), } 20 \text { (51-VI-1), } \\
\quad 38 \text { (51-VI- } 2)\end{array}$ & 2000 \\
\hline 32461 & Fusarium virguliforme & Fsg-ISU 4 & Glycine $\max$ & USA, Iowa-Chickasaw & $\begin{array}{l}20 \text { (96-VI-1), } 19 \text { (51-VI-1), } \\
37 \text { (51-VI-2) }\end{array}$ & 2000 \\
\hline 32464 & Fusarium virguliforme & Fsg-ISU 7 & Glycine $\max$ & USA, Iowa-Clinton & $\begin{array}{l}23 \text { (96-VI-1), } 24 \text { (51-VI-1), } \\
\quad 44 \text { (51-VI-2) }\end{array}$ & 1995 \\
\hline
\end{tabular}

${ }^{a}$ NRRL = Agriculture Research Service Culture Collection, National Center for Agricultural Utilization Research, USDA-ARS, Peoria, IL.

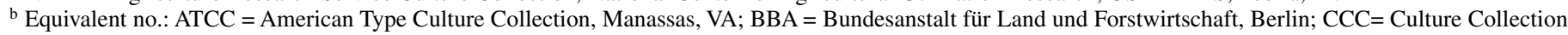
of CEREMIC (Centro de Referencia de Micología), Fac. de Cs. Bioquímicas y Farmacéuticas, UNR, Rosario, Argentina; FRC = Fusarium Research Center, Department of Plant Pathology, Pennsylvania State University, University Park, PA; Fsg-ISU = Department of Plant Pathology, Iowa State University, Ames, IA; MAFF = NIAS Genbank-Microorganisms Section, National Institute of Agrobiological Sciences (NIAS), 2-1-2 Kannondai, Tsukuba, Ibaraki 305-8602, Japan; NSPCC $=$ National Soybean Pathogen Culture Collection, ARS-USDA, Urbana, IL.

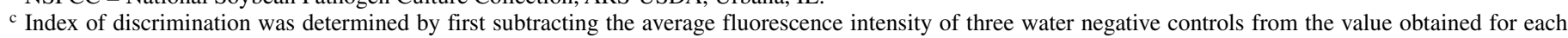
DNA sample, and then dividing the minimum fluorescence intensity (MFI) by the maximum nontarget fluorescence intensity. Species-specific primer probes are indicated in parentheses (Table 3 provides probes used in the assay).

d Sequence data from locus 96 were used to identify NRRL 46137 as Fusarium tucumaniae. 
TABLE 2. (Continued from preceeding page)

\begin{tabular}{|c|c|c|c|c|c|c|}
\hline NRRL $^{\mathrm{a}}$ & Species & Equivalent no. $^{\mathrm{b}}$ & Host & Origin & $\begin{array}{c}\text { Index of } \\
\text { discrimination }{ }^{c}\end{array}$ & $\begin{array}{l}\text { Year } \\
\text { isolated }\end{array}$ \\
\hline 32465 & Fusarium virguliforme & Fsg-ISU 8 & Glycine max & USA, Iowa-Clinton & $\begin{array}{l}23 \text { (96-VI-1), } 22 \text { (51-VI-1) } \\
\quad 42 \text { (51-VI-2) }\end{array}$ & 1995 \\
\hline 32467 & Fusarium virguliforme & Fsg-ISU 10 & Glycine $\max$ & USA, Iowa-Floyd & $\begin{array}{l}23 \text { (96-VI-1), } 22 \text { (51-VI-1), } \\
\quad 42 \text { (51-VI-2) }\end{array}$ & 1994 \\
\hline 32468 & Fusarium virguliforme & Fsg-ISU 11 & Glycine max & USA, Iowa-Greene & $\begin{array}{l}22 \text { (96-VI-1), } 20 \text { (51-VI-1), } \\
\quad 39 \text { (51-VI-2) }\end{array}$ & 1996 \\
\hline 32471 & Fusarium virguliforme & Fsg-ISU 14 & Glycine $\max$ & USA, Iowa-Jasper & $\begin{array}{l}23 \text { (96-VI-1), } 25 \text { (51-VI-1), } \\
\quad 44 \text { (51-VI-2) }\end{array}$ & 1994 \\
\hline 32476 & Fusarium virguliforme & Fsg-ISU 19 & Glycine max & USA, Missouri-Mont & $\begin{array}{l}22 \text { (96-VI-1), } 25 \text { (51-VI-1), } \\
\quad 45 \text { (51-VI-2) }\end{array}$ & Prior 1993 \\
\hline 32479 & Fusarium virguliforme & Fsg-ISU 22 & Glycine max & USA, Iowa-Scott & $\begin{array}{l}22 \text { (96-VI-1), } 22 \text { (51-VI-1) } \\
\quad 42 \text { (51-VI-2) }\end{array}$ & 1993 \\
\hline 32480 & Fusarium virguliforme & Fsg-ISU 23 & Glycine $\max$ & USA, Iowa-Worth & $\begin{array}{l}23 \text { (96-VI-1), } 25 \text { (51-VI-1) } \\
\quad 49 \text { (51-VI-2) }\end{array}$ & 1995 \\
\hline 34438 & Fusarium virguliforme & FRC S-1288L = Gray 17-1 & Glycine $\max$ & USA, Arkansas & $\begin{array}{l}19 \text { (96-VI-1), } 19 \text { (51-VI-1), } \\
37 \text { (51-VI-2) }\end{array}$ & Prior 1993 \\
\hline 34439 & Fusarium virguliforme & FRC S-1292L = Gray 12W-1 & Glycine $\max$ & USA, Illinois & $\begin{array}{l}24 \text { (96-VI-1), } 27 \text { (51-VI-1), } \\
\quad 45 \text { (51-VI-2) }\end{array}$ & 1991 \\
\hline 34440 & Fusarium virguliforme & FRC S-1294L = Gray RW-1 & Glycine $\max$ & USA, Illinois & $\begin{array}{l}23 \text { (96-VI-1), } 22 \text { (51-VI-1), } \\
\quad 42 \text { (51-VI-2) }\end{array}$ & 1991 \\
\hline 34441 & Fusarium virguliforme & FRC S-1295L = Gray Mont-1 & Glycine max & USA, Illinois & 27 (51-VI-1), 56 (51-VI-2) & 1991 \\
\hline 34442 & Fusarium virguliforme & FRC S-1296L = Gray 1990-1 & Glycine $\max$ & USA, Illinois & $\begin{array}{l}24 \text { (96-VI-1), } 30 \text { (51-VI-1), } \\
\quad 52 \text { (51-VI-2) }\end{array}$ & 1990 \\
\hline 34443 & Fusarium virguliforme & FRC S-1298L = Gray 11A-1 & Glycine $\max$ & USA, Illinois & $\begin{array}{l}24 \text { (96-VI-1), } 27 \text { (51-VI-1) } \\
\quad 49 \text { (51-VI-2) }\end{array}$ & 1991 \\
\hline 34444 & Fusarium virguliforme & FRC S-1299L = Gray St9055-1 & Glycine $\max$ & USA, Illinois & $\begin{array}{l}24 \text { (96-VI-1), } 24 \text { (51-VI-1) } \\
\quad 46 \text { (51-VI-2) }\end{array}$ & 1990 \\
\hline 34547 & Fusarium tucumaniae & MAFF $239253=$ CCC 126-02 & Glycine max & $\begin{array}{l}\text { Argentina, Las Parejas, } \\
\text { Santa Fe }\end{array}$ & 14 (TU-a), 16 (TU-C) & 2001 \\
\hline 34548 & Fusarium tucumaniae & MAFF $239254=$ CCC 127-02 & Glycine max & $\begin{array}{l}\text { Argentina, Las Parejas, } \\
\text { Santa Fe }\end{array}$ & 13 (TU-a), 17 (TU-C) & 2001 \\
\hline 34549 & Fusarium tucumaniae & MAFF 239255 = CCC 129-02 & Glycine $\max$ & $\begin{array}{l}\text { Argentina, Perez Millan, } \\
\text { Buenos Aires }\end{array}$ & 14 (TU-a), 18 (TU-C) & 2000 \\
\hline 34550 & Fusarium tucumaniae & MAFF $239256=$ CCC 128-02 & Glycine $\max$ & Argentina, Pujato, Santa Fe & 13 (TU-a), 17 (TU-C) & 2000 \\
\hline 34551 & Fusarium virguliforme & MAFF $239257=$ CCC 101-03 & Glycine $\max$ & $\begin{array}{l}\text { Argentina, San Pedro, } \\
\text { Buenos Aires }\end{array}$ & $\begin{array}{l}19 \text { (96-VI-1), } 23 \text { (51-VI-1), } \\
37 \text { (51-VI-2) }\end{array}$ & 2002 \\
\hline 34552 & Fusarium virguliforme & MAFF $239258=$ CCC 102-03 & Glycine max & Argentina, Serodino, Santa Fe & $\begin{array}{l}18 \text { (96-VI-1), } 25 \text { (51-VI-1), } \\
\quad 38 \text { (51-VI-2) }\end{array}$ & 2002 \\
\hline 34553 & Fusarium virguliforme & MAFF $239259=$ CCC 103-03 & Glycine max & Argentina, Serodino, Santa Fe & $\begin{array}{l}16 \text { (96-VI-1), } 21 \text { (51-VI-1), } \\
\quad 34 \text { (51-VI-2) }\end{array}$ & 2002 \\
\hline 34938 & Fusarium brasiliense & CD 203 & Glycine $\max$ & $\begin{array}{l}\text { Brasil, Passo Fundo, Rio } \\
\text { Grande do Sul }\end{array}$ & 30 (B-a), 7 (B-b) & 2003 \\
\hline 34939 & Fusarium tucumaniae & BRS 137 & Glycine max & $\begin{array}{l}\text { Brasil, Passo Fundo, Rio } \\
\text { Grande do Sul }\end{array}$ & 13 (TU-a), 15 (TU-C) & 2003 \\
\hline 36023 & Fusarium cuneirostrum & Mung 1 & Vigna radiata & Canada, Ontario, Ridgetown & $8(\mathrm{CU}-\mathrm{a})$ & 1996 \\
\hline 36024 & Fusarium cuneirostrum & Mung 2 & Vigna radiata & Canada, Ontario, Ridgetown & $12(\mathrm{CU}-\mathrm{a})$ & 1996 \\
\hline 36604 & Fusarium virguliforme & CCC $155-05$ & Soil & $\begin{array}{l}\text { Argentina, Buenos Aires, } \\
\text { Pergamino }\end{array}$ & $\begin{array}{l}17 \text { (96-VI-1), } 22 \text { (51-VI-1), } \\
\quad 37 \text { (51-VI-2) }\end{array}$ & Unknown \\
\hline 36605 & Fusarium virguliforme & CCC 156-05 & Soil & $\begin{array}{l}\text { Argentina, Buenos Aires, } \\
\text { Pergamino }\end{array}$ & $\begin{array}{l}17 \text { (96-VI-1), } 23 \text { (51-VI-1), } \\
\quad 35 \text { (51-VI-2) }\end{array}$ & Unknown \\
\hline 36606 & Fusarium virguliforme & CCC 157-05 & Soil & $\begin{array}{l}\text { Argentina, Buenos Aires, } \\
\text { Pergamino }\end{array}$ & $\begin{array}{l}17 \text { (96-VI-1), } 20 \text { (51-VI-1), } \\
\quad 32 \text { (51-VI-2) }\end{array}$ & Unknown \\
\hline 36607 & Fusarium virguliforme & CCC 158-05 & Soil & $\begin{array}{l}\text { Argentina, Buenos Aires, } \\
\text { Pergamino }\end{array}$ & $\begin{array}{l}16 \text { (96-VI-1), } 20 \text { (51-VI-1), } \\
\quad 34 \text { (51-VI-2) }\end{array}$ & Unknown \\
\hline 36609 & Fusarium tucumaniae & CCC 161-05 & Soil & $\begin{array}{l}\text { Argentina, Buenos Aires, } \\
\text { Pergamino }\end{array}$ & 12 (TU-a), 14 (TU-C) & Unknown \\
\hline 36610 & Fusarium virguliforme & CCC 159-05 & Soil & $\begin{array}{l}\text { Argentina, Buenos Aires, } \\
\text { Pergamino }\end{array}$ & $\begin{array}{l}18 \text { (96-VI-1), } 21 \text { (51-VI-1), } \\
\quad 32 \text { (51-VI-2) }\end{array}$ & Unknown \\
\hline 36611 & Fusarium virguliforme & CCC 160-05 & Soil & $\begin{array}{l}\text { Argentina, Buenos Aires, } \\
\text { Pergamino }\end{array}$ & $\begin{array}{l}17 \text { (96-VI-1), } 23 \text { (51-VI-1), } \\
\quad 35 \text { (51-VI-2) }\end{array}$ & Unknown \\
\hline 36612 & Fusarium tucumaniae & CCC $162-05$ & Soil & $\begin{array}{l}\text { Argentina, Buenos Aires, } \\
\text { Pergamino }\end{array}$ & 13 (TU-a), 16 (TU-C) & Unknown \\
\hline 36613 & Fusarium tucumaniae & CCC 163-05 & Soil & $\begin{array}{l}\text { Argentina, Buenos Aires, } \\
\text { Pergamino }\end{array}$ & 13 (TU-a), 16 (TU-C) & Unknown \\
\hline 36877 & Fusarium sp. & MAFF $239757=$ CCC 142-05 & Glycine $\max$ & Argentina, Zavalla, Santa Fe & 36 (CR-a), 14 (CR-b) & 2004 \\
\hline 36878 & Fusarium tucumaniae & CCC 209-05 & Glycine $\max$ & Argentina, Zavalla, Santa Fe & 12 (TU-a), 14 (TU-C) & 2004 \\
\hline 36879 & Fusarium tucumaniae & CCC 210-05 & Glycine $\max$ & Argentina, Zavalla, Santa Fe & 13 (TU-a), 16 (TU-C) & 2004 \\
\hline 36880 & Fusarium tucumaniae & CCC 211-05 & Glycine $\max$ & $\begin{array}{l}\text { Argentina, Los Molinos, } \\
\text { Santa Fe }\end{array}$ & 13 (TU-a), 18 (TU-C) & 2004 \\
\hline 36883 & Fusarium tucumaniae & CCC 212-05 & Glycine max & $\begin{array}{l}\text { Argentina, Los Molinos, } \\
\text { Santa Fe }\end{array}$ & 12 (TU-a), 18 (TU-C) & 2004 \\
\hline
\end{tabular}




\begin{tabular}{|c|c|c|c|c|c|c|}
\hline NRRL $^{\mathrm{a}}$ & Species & Equivalent no. ${ }^{\mathrm{b}}$ & Host & Origin & $\begin{array}{c}\text { Index of } \\
\text { discrimination }^{c}\end{array}$ & $\begin{array}{l}\text { Year } \\
\text { isolated }\end{array}$ \\
\hline 36886 & Fusarium tucumaniae & CCC 154-06 & Glycine $\max$ & Argentina, Los Molinos, Santa Fe & 16 (TU-C) & 2004 \\
\hline 36887 & Fusarium tucumaniae & CCC 213-05 & Glycine max & Argentina, Los Molinos, Santa Fe & 12 (TU-a), 16 (TU-C) & 2004 \\
\hline 36888 & Fusarium tucumaniae & CCC 214-05 & Glycine $\max$ & Argentina, Los Molinos, Santa Fe & 12 (TU-a), 15 (TU-C) & 2004 \\
\hline 36895 & Fusarium tucumaniae & CCC 215-05 & Glycine $\max$ & Argentina, Los Molinos, Santa Fe & $14(\mathrm{TU}-\mathrm{a})$ & 2004 \\
\hline 36896 & Fusarium virguliforme & CCC 216-05 & Glycine $\max$ & Argentina, Los Molinos, Santa Fe & $\begin{array}{l}17 \text { (96-VI-1), } 22 \text { (51-VI-1), } 35 \\
\quad(51-\mathrm{VI}-2)\end{array}$ & 2004 \\
\hline 36897 & Fusarium virguliforme & CCC 217-05 & Glycine $\max$ & Argentina, Los Molinos, Santa Fe & $\begin{array}{l}17 \text { (96-VI-1), } 21 \text { (51-VI-1), } 35 \\
\quad(51-V I-2)\end{array}$ & 2004 \\
\hline 36898 & Fusarium virguliforme & CCC 218-05 & Glycine max & Argentina, Los Molinos, Santa Fe & $\begin{array}{l}9 \text { (96-VI-1), } 11 \text { (51-VI-1), } 23 \\
\quad(51-\mathrm{VI}-2)\end{array}$ & 2004 \\
\hline 36899 & Fusarium virguliforme & CCC 219-05 & Glycine $\max$ & Argentina, Los Molinos, Santa Fe & $\begin{array}{l}17 \text { (96-VI-1), } 19 \text { (51-VI-1), } 32 \\
\quad(51-\mathrm{VI}-2)\end{array}$ & 2004 \\
\hline 36900 & Fusarium virguliforme & CCC 220-05 & Glycine $\max$ & Argentina, Los Molinos, Santa Fe & $\begin{array}{l}14 \text { (96-VI-1), } 16 \text { (51-VI-1), } 30 \\
\quad(51-\mathrm{VI}-2)\end{array}$ & 2004 \\
\hline 37585 & Fusarium virguliforme & NSPCC i1 & Glycine $\max$ & USA, Arkansas & $\begin{array}{l}16 \text { (96-VI-1), } 19 \text { (51-VI-1), } 33 \\
\quad(51-\mathrm{VI}-2)\end{array}$ & 1991 \\
\hline 37586 & Fusarium virguliforme & NSCPP i12 & Glycine max & USA, Arkansas & $\begin{array}{l}15 \text { (96-VI-1), } 16 \text { (51-VI-1), } 29 \\
\quad(51-\mathrm{VI}-2)\end{array}$ & 1996 \\
\hline 37587 & Fusarium virguliforme & NSCPP i45 & Glycine $\max$ & USA, Illinois & $\begin{array}{l}14 \text { (96-VI-1), } 17 \text { (51-VI-1), } 29 \\
\quad(51-\mathrm{VI}-2)\end{array}$ & 1994 \\
\hline 37588 & Fusarium virguliforme & NSCPP i98 & Glycine $\max$ & USA, Wisconson & $\begin{array}{l}15 \text { (96-VI-1), } 17 \text { (51-VI-1), } 30 \\
\quad(51-\mathrm{VI}-2)\end{array}$ & 1998 \\
\hline 37589 & Fusarium virguliforme & NSCPP i300 & Glycine $\max$ & USA, Illinois & $\begin{array}{l}16 \text { (96-VI-1), } 17 \text { (51-VI-1), } 32 \\
\quad(51-\mathrm{VI}-2)\end{array}$ & 1991 \\
\hline 37590 & Fusarium virguliforme & NSCPP i502 & Glycine $\max$ & USA, Missouri & $\begin{array}{l}16 \text { (96-VI-1), } 20 \text { (51-VI-1), } 35 \\
\quad(51-\mathrm{VI}-2)\end{array}$ & 2002 \\
\hline 37591 & Fusarium virguliforme & NSCPP i506 & Glycine max & USA, Missouri & $\begin{array}{l}15 \text { (96-VI-1), } 16 \text { (51-VI-1), } 26 \\
\quad(51-\mathrm{VI}-2)\end{array}$ & 2002 \\
\hline 37592 & Fusarium virguliforme & NSCPP i530 & Glycine $\max$ & USA, Indiana & $\begin{array}{l}14 \text { (96-VI-1), } 17 \text { (51-VI-1), } 28 \\
\quad(51-\mathrm{VI}-2)\end{array}$ & 2003 \\
\hline 38411 & Fusarium tucumaniae & CCC 164-05 & Glycine max & Argentina, General Roca, Córdoba & 13 (TU-a), 13 (TU-c) & 2005 \\
\hline 38412 & Fusarium tucumaniae & CCC $165-05$ & Glycine $\max$ & Argentina, General Roca, Córdoba & 12 (TU-a), 16 (TU-c) & 2005 \\
\hline 38413 & Fusarium tucumaniae & CCC 166-05 & Glycine $\max$ & Argentina, General Roca, Córdoba & 11 (TU-a), 15 (TU-c) & 2005 \\
\hline 38414 & Fusarium tucumaniae & CCC 167-05 & Glycine max & Argentina, General Roca, Córdoba & 12 (TU-a), 13 (TU-c) & 2005 \\
\hline 38415 & Fusarium tucumaniae & CCC 168-05 & Glycine $\max$ & Argentina, General Roca, Córdoba & 13 (TU-a), 16 (TU-c) & 2005 \\
\hline 38416 & Fusarium tucumaniae & CCC 169-05 & Glycine max & Argentina, General Roca, Córdoba & 11 (TU-a), 15 (TU-c) & 2005 \\
\hline 38417 & Fusarium virguliforme & CCC $170-05$ & Glycine $\max$ & Argentina, Cañada de Gómez, Santa Fe & $\begin{array}{l}15 \text { (96-VI-1), } 20 \text { (51-VI-1), } 35 \\
\quad(51-\mathrm{VI}-2)\end{array}$ & 2005 \\
\hline 38418 & Fusarium tucumaniae & CCC 171-05 & Glycine max & Argentina, Cañada de Gómez, Santa Fe & 12 (TU-a), 17 (TU-c) & 2005 \\
\hline 38419 & Fusarium tucumaniae & CCC 173-05 & Glycine $\max$ & Argentina, Cañada de Gómez, Santa Fe & 13 (TU-a), 17 (TU-c) & 2005 \\
\hline 38420 & Fusarium tucumaniae & CCC 174-05 & Glycine max & Argentina, Cañada de Gómez, Santa Fe & 14 (TU-a), 19 (TU-c) & 2005 \\
\hline 43326 & Fusarium tucumaniae & CCC 105-06 & Glycine $\max$ & Argentina, Monte Buey, Córdoba & 13 (TU-a), 19 (TU-c) & 2006 \\
\hline 43327 & Fusarium tucumaniae & CCC 158-06 & Glycine $\max$ & Argentina, Monte Buey, Córdoba & 14 (TU-a), 18 (TU-c) & 2006 \\
\hline 43328 & Fusarium tucumaniae & CCC 157-06 & Glycine $\max$ & Argentina, Monte Buey, Córdoba & 11 (TU-a), 16 (TU-c) & 2006 \\
\hline 43329 & Fusarium tucumaniae & CCC 159-06 & Glycine max & Argentina, Monte Buey, Córdoba & 11 (TU-a), 20 (TU-c) & 2006 \\
\hline 43331 & Fusarium tucumaniae & CCC 132-06 & Glycine max & Argentina, Armstrong, Santa Fe & 13 (TU-a), 16 (TU-c) & 2006 \\
\hline 43332 & Fusarium tucumaniae & CCC 156-06 & Glycine $\max$ & Argentina, Armstrong, Santa Fe & 14 (TU-a), 18 (TU-c) & 2006 \\
\hline 43333 & Fusarium tucumaniae & CCC 133-06 & Glycine $\max$ & Argentina, Armstrong, Santa Fe & 13 (TU-a), 21 (TU-c) & 2006 \\
\hline 43334 & Fusarium tucumaniae & CCC 104-06 & Glycine max & Argentina, Armstrong, Santa Fe & 15 (TU-a), 24 (TU-c) & 2006 \\
\hline 43335 & Fusarium tucumaniae & CCC 134-06 & Glycine max & Argentina, Armstrong, Santa Fe & 14 (TU-a), 19 (TU-c) & 2006 \\
\hline 43336 & Fusarium tucumaniae & CCC 160-06 & Glycine $\max$ & Argentina, Gral. Roca, Córdoba & 13 (TU-a), 17 (TU-c) & 2006 \\
\hline 43337 & Fusarium tucumaniae & CCC 167-06 & Glycine max & Argentina, Gral. Roca, Córdoba & 13 (TU-a), 16 (TU-c) & 2006 \\
\hline 43338 & Fusarium tucumaniae & CCC 139-06 & Glycine $\max$ & Argentina, Gral. Roca, Córdoba & 12 (TU-a), 16 (TU-c) & 2006 \\
\hline 43339 & Fusarium tucumaniae & CCC 140-06 & Glycine $\max$ & Argentina, Gral. Roca, Córdoba & 12 (TU-a), 15 (TU-c) & 2006 \\
\hline 43340 & Fusarium tucumaniae & CCC 141-06 & Glycine max & Argentina, Gral. Roca, Córdoba & 11 (TU-a), 17 (TU-c) & 2006 \\
\hline 43341 & Fusarium tucumaniae & CCC 108-06 & Glycine max & Argentina, Gral. Roca, Córdoba & 11 (TU-a), 22 (TU-c) & 2006 \\
\hline 43342 & Fusarium tucumaniae & CCC 164-06 & Glycine $\max$ & Argentina, Monte Buey, Córdoba & 12 (TU-a), 18 (TU-c) & 2006 \\
\hline 43343 & Fusarium tucumaniae & CCC 109-06 & Glycine $\max$ & Argentina, Marcos Juárez, Córdoba & 13 (TU-a), 14 (TU-c) & 2006 \\
\hline 43344 & Fusarium tucumaniae & CCC 163-06 & Glycine max & Argentina, Marcos Juárez, Córdoba & 12 (TU-a), 18 (TU-c) & 2006 \\
\hline 43345 & Fusarium tucumaniae & CCC 142-06 & Glycine max & Argentina, Marcos Juárez, Córdoba & 14 (TU-a), 20 (TU-c) & 2006 \\
\hline 43346 & Fusarium tucumaniae & CCC 143-06 & Glycine max & Argentina, Marcos Juárez, Córdoba & 8 (TU-a), 10 (TU-c) & 2006 \\
\hline 43347 & Fusarium tucumaniae & CCC 144-06 & Glycine $\max$ & Argentina, Marcos Juárez, Córdoba & 12 (TU-a), 17 (TU-c) & 2006 \\
\hline 43348 & Fusarium tucumaniae & $06-232-1$ & Glycine $\max$ & Argentina, Corral de Bustos, Córdoba & 12 (TU-a), 17 (TU-c) & 2006 \\
\hline 43349 & Fusarium tucumaniae & CCC 138-06 & Glycine $\max$ & Argentina, Corral de Bustos, Córdoba & 11 (TU-a), 16 (TU-c) & 2006 \\
\hline 43350 & Fusarium brasiliense & CCC 161-06 & Glycine $\max$ & Argentina, Saira, Córdoba & 69 (B-a), 8 (B-b) & 2006 \\
\hline 43351 & Fusarium tucumaniae & CCC 110-06 & Glycine max & Argentina, Saira, Córdoba & 12 (TU-a), 17 (TU-c) & 2006 \\
\hline 43352 & Fusarium tucumaniae & CCC 113-06 & Glycine $\max$ & Argentina, Chañar Ladeado, Santa Fe & 12 (TU-a), 18 (TU-c) & 2006 \\
\hline 43353 & Fusarium tucumaniae & CCC 107-06 & Glycine max & Argentina, Chañar Ladeado, Santa Fe & 10 (TU-a), 16 (TU-c) & 2006 \\
\hline 43354 & Fusarium tucumaniae & CCC 114-06 & Glycine $\max$ & Argentina, Chañar Ladeado, Santa Fe & 12 (TU-a), 16 (TU-c) & 2006 \\
\hline 43355 & Fusarium tucumaniae & CCC 115-06 & Glycine $\max$ & Argentina, Chañar Ladeado, Santa Fe & 9 (TU-a), 12 (TU-c) & 2006 \\
\hline 43356 & Fusarium tucumaniae & CCC 116-06 & Glycine max & Argentina, Chañar Ladeado, Santa Fe & 9 (TU-a), 13 (TU-c) & 2006 \\
\hline 43357 & Fusarium tucumaniae & CCC 165-06 & Glycine max & Argentina, Chañar Ladeado, Santa Fe & 11 (TU-a), 16 (TU-c) & 2006 \\
\hline
\end{tabular}




\begin{tabular}{|c|c|c|c|c|c|c|}
\hline NRRL $^{a}$ & Species & Equivalent no. ${ }^{b}$ & Host & Origin & $\begin{array}{c}\text { Index of } \\
\text { discrimination }^{c}\end{array}$ & $\begin{array}{c}\text { Year } \\
\text { isolated }\end{array}$ \\
\hline 43358 & Fusarium tucumaniae & CCC 117-06 & Glycine $\max$ & Argentina, Chañar Ladeado, Santa Fe & 14 (TU-a), 16 (TU-c) & 2006 \\
\hline 43359 & Fusarium tucumaniae & CCC 118-06 & Glycine max & Argentina, Chañar Ladeado, Santa Fe & 13 (TU-a), 16 (TU-c) & 2006 \\
\hline 43360 & Fusarium tucumaniae & CCC 119-06 & Glycine $\max$ & Argentina, Chañar Ladeado, Santa Fe & 11 (TU-a), 14 (TU-c) & 2006 \\
\hline 43361 & Fusarium tucumaniae & CCC 166-06 & Glycine $\max$ & Argentina, Chañar Ladeado, Santa Fe & 11 (TU-a), 15 (TU-c) & 2006 \\
\hline 43362 & Fusarium tucumaniae & CCC 106-06 & Glycine $\max$ & Argentina, Victoria, Entre Ríos & 11 (TU-a), 17 (TU-c) & 2006 \\
\hline 43363 & Fusarium tucumaniae & CCC $135-06$ & Glycine $\max$ & Argentina, Victoria, Entre Ríos & 11 (TU-a), 16 (TU-c) & 2006 \\
\hline 43364 & Fusarium tucumaniae & CCC 136-06 & Glycine max & Argentina, Victoria, Entre Ríos & 11 (TU-a), 18 (TU-c) & 2006 \\
\hline 43365 & Fusarium tucumaniae & CCC 137-06 & Glycine $\max$ & Argentina, Victoria, Entre Ríos & 11 (TU-a), 18 (TU-c) & 2006 \\
\hline 43366 & Fusarium tucumaniae & CCC 207-07 & Glycine $\max$ & Argentina, Victoria, Entre Ríos & 10 (TU-a), 14 (TU-c) & 2006 \\
\hline 43367 & Fusarium tucumaniae & CCC 129-06 & Glycine $\max$ & Argentina, Leones, Córdoba & 12 (TU-a), 13 (TU-c) & 2006 \\
\hline 43368 & Fusarium tucumaniae & CCC 130-06 & Glycine $\max$ & Argentina, Leones, Córdoba & 13 (TU-a), 16 (TU-c) & 2006 \\
\hline 43369 & Fusarium tucumaniae & CCC 112-06 & Glycine $\max$ & Argentina, Leones, Córdoba & 14 (TU-a), 16 (TU-c) & 2006 \\
\hline 43370 & Fusarium tucumaniae & CCC 131-06 & Glycine max & Argentina, Leones, Córdoba & 14 (TU-a), 22 (TU-c) & 2006 \\
\hline 43371 & Fusarium tucumaniae & $06-281-1$ & Glycine $\max$ & Argentina, Tortugas, Santa Fe & 13 (TU-a), 18 (TU-c) & 2006 \\
\hline 43559 & Fusarium tucumaniae & CCC 145-06 & Glycine $\max$ & Argentina, Tortugas, Santa Fe & 12 (TU-a), 16 (TU-c) & 2006 \\
\hline 43560 & Fusarium tucumaniae & CCC 146-06 & Glycine $\max$ & Argentina, Tortugas, Santa Fe & 10 (TU-a), 14 (TU-c) & 2006 \\
\hline 43561 & Fusarium tucumaniae & CCC 111-06 & Glycine $\max$ & Argentina, Tortugas, Santa Fe & 11 (TU-a), 13 (TU-c) & 2006 \\
\hline 43562 & Fusarium tucumaniae & CCC 147-06 & Glycine $\max$ & Argentina, Tortugas, Santa Fe & 11 (TU-a), 17 (TU-c) & 2006 \\
\hline 43563 & Fusarium tucumaniae & CCC 148-06 & Glycine $\max$ & Argentina, Tortugas, Santa Fe & 11 (TU-a), 20 (TU-c) & 2006 \\
\hline 43564 & Fusarium tucumaniae & CCC 149-06 & Glycine $\max$ & Argentina, Tortugas, Santa $\mathrm{Fe}$ & 11 (TU-a), 14 (TU-c) & 2006 \\
\hline 43565 & Fusarium tucumaniae & CCC 150-06 & Glycine $\max$ & Argentina, Tortugas, Santa Fe & 11 (TU-a), 15 (TU-c) & 2006 \\
\hline 43566 & Fusarium tucumaniae & CCC 151-06 & Glycine $\max$ & Argentina, Tortugas, Santa Fe & 10 (TU-a), 13 (TU-c) & 2006 \\
\hline 43567 & Fusarium tucumaniae & CCC $152-06$ & Glycine $\max$ & Argentina, Tortugas, Santa Fe & 12 (TU-a), 16 (TU-c) & 2006 \\
\hline 43568 & Fusarium tucumaniae & CCC 153-06 & Glycine $\max$ & Argentina, Tortugas, Santa Fe & 14 (TU-a), 18 (TU-c) & 2006 \\
\hline 43569 & Fusarium tucumaniae & CCC $120-06$ & Glycine $\max$ & Argentina, Justiniano Posse, Córdoba & 13 (TU-a), 20 (TU-c) & 2006 \\
\hline 43570 & Fusarium tucumaniae & CCC 121-06 & Glycine $\max$ & Argentina, Justiniano Posse, Córdoba & 12 (TU-a), 16 (TU-c) & 2006 \\
\hline 43571 & Fusarium tucumaniae & CCC 103-06 & Glycine $\max$ & Argentina, Justiniano Posse, Córdoba & 7 (TU-a), 7 (TU-c) & 2006 \\
\hline 43572 & Fusarium tucumaniae & CCC 122-06 & Glycine $\max$ & Argentina, Justiniano Posse, Córdoba & 9 (TU-a), 13 (TU-c) & 2006 \\
\hline 43574 & Fusarium tucumaniae & CCC 124-06 & Glycine $\max$ & Argentina, Justiniano Posse, Córdoba & 10 (TU-a), 16 (TU-c) & 2006 \\
\hline 43575 & Fusarium tucumaniae & CCC 125-06 & Glycine $\max$ & Argentina, Justiniano Posse, Córdoba & 12 (TU-a), 20 (TU-c) & 2006 \\
\hline 43576 & Fusarium tucumaniae & CCC 126-06 & Glycine $\max$ & Argentina, Justiniano Posse, Córdoba & 11 (TU-a), 17 (TU-c) & 2006 \\
\hline 43577 & Fusarium tucumaniae & CCC $127-06$ & Glycine $\max$ & Argentina, Justiniano Posse, Córdoba & 12 (TU-a), 13 (TU-c) & 2006 \\
\hline 43578 & Fusarium tucumaniae & CCC 128-06 & Glycine $\max$ & Argentina, Justiniano Posse, Córdoba & 11 (TU-a), 15 (TU-c) & 2006 \\
\hline 43824 & Fusarium sp. & CCC 144-07 & Glycine max & Argentina, Las Cejas, Tucumán & $36(\mathrm{CR}-\mathrm{a}), 8(\mathrm{CR}-\mathrm{b})$ & 2006 \\
\hline 43825 & Fusarium sp. & CCC 143-07 & Glycine $\max$ & Argentina, Las Cejas, Tucumán & 36 (CR-a), 8 (CR-b) & 2006 \\
\hline 43826 & Fusarium tucumaniae & CCC 204-07 & Glycine $\max$ & Argentina, Las Cejas, Tucumán & 13 (TU-a), 21 (TU-c) & 2006 \\
\hline 43827 & Fusarium tucumaniae & CCC 142-07 & Glycine $\max$ & Argentina, Las Cejas, Tucumán & 12 (TU-a), 15 (TU-c) & 2006 \\
\hline 43828 & Fusarium tucumaniae & CCC 141-07 & Glycine $\max$ & Argentina, Las Cejas, Tucumán & 11 (TU-a), 14 (TU-c) & 2006 \\
\hline 43829 & Fusarium tucumaniae & CCC 140-07 & Glycine max & Argentina, Las Cejas, Tucumán & 9 (TU-a), 12 (TU-c) & 2006 \\
\hline 43830 & Fusarium tucumaniae & CCC 205-07 & Glycine $\max$ & Argentina, Las Cejas, Tucumán & $14(\mathrm{TU}-\mathrm{c})$ & 2006 \\
\hline 43831 & Fusarium tucumaniae & CCC 206-07 & Glycine $\max$ & Argentina, Las Cejas, Tucumán & 15 (TU-c) & 2006 \\
\hline 43832 & Fusarium tucumaniae & CCC 207-07 & Glycine $\max$ & Argentina, Las Cejas, Tucumán & 11 (TU-a), 17 (TU-c) & 2006 \\
\hline 43833 & Fusarium tucumaniae & CCC139-07 & Glycine $\max$ & Argentina, Las Cejas, Tucumán & $18(\mathrm{TU}-\mathrm{c})$ & 2006 \\
\hline 43834 & Fusarium tucumaniae & CCC 144-07 & Glycine $\max$ & Argentina, Las Cejas, Tucumán & $15(\mathrm{TU}-\mathrm{c})$ & 2006 \\
\hline 43835 & Fusarium tucumaniae & CCC 208-07 & Glycine $\max$ & Argentina, Las Cejas, Tucumán & 15 (TU-c) & 2006 \\
\hline 43837 & Fusarium tucumaniae & $06-223-2$ & Glycine $\max$ & Argentina, Monte Buey, Córdoba & 14 (TU-a), 22 (TU-c) & 2006 \\
\hline 43838 & Fusarium tucumaniae & CCC 147-07 & Glycine $\max$ & Argentina, Monte Buey, Córdoba & 14 (TU-a), 22 (TU-c) & 2006 \\
\hline 43839 & Fusarium tucumaniae & $06-223-4$ & Glycine $\max$ & Argentina, Monte Buey, Córdoba & 14 (TU-a), 17 (TU-c) & 2006 \\
\hline 43840 & Fusarium tucumaniae & CCC $145-07$ & Glycine $\max$ & Argentina, Monte Buey, Córdoba & 12 (TU-a), 14 (TU-c) & 2006 \\
\hline 43842 & Fusarium tucumaniae & $06-225-2$ & Glycine max & Argentina, Camilo Aldao, Córdoba & $15(\mathrm{TU}-\mathrm{c})$ & 2006 \\
\hline 43843 & Fusarium tucumaniae & CCC 146-07 & Glycine $\max$ & Argentina, Camilo Aldao, Córdoba & 3 (TU-c) & 2006 \\
\hline 43844 & Fusarium tucumaniae & $06-225-4$ & Glycine $\max$ & Argentina, Camilo Aldao, Córdoba & 17 (TU-c) & 2006 \\
\hline 43845 & Fusarium tucumaniae & $06-225-5$ & Glycine $\max$ & Argentina, Camilo Aldao, Córdoba & 17 (TU-c) & 2006 \\
\hline 46129 & Fusarium tucumaniae & CCC 116-07 & Glycine $\max$ & Argentina, Gral.Roca, Córdoba & $8($ TU-a), 8 (TU-c) & 2007 \\
\hline 46130 & Fusarium tucumaniae & CCC 117-07 & Glycine $\max$ & Argentina, Gral.Roca, Córdoba & 13 (TU-a), 20 (TU-c) & 2007 \\
\hline 46131 & Fusarium tucumaniae & CCC 118-07 & Glycine $\max$ & Argentina, Gral.Roca, Córdoba & 13 (TU-a), 20 (TU-c) & 2007 \\
\hline 46132 & Fusarium tucumaniae & CCC $119-07$ & Glycine $\max$ & Argentina, Gral.Roca, Córdoba & 12 (TU-a), 22 (TU-c) & 2007 \\
\hline 46133 & Fusarium tucumaniae & CCC 109-07 & Glycine $\max$ & Argentina, Inriville, Córdoba & 15 (TU-a), 25 (TU-c) & 2007 \\
\hline 46134 & Fusarium tucumaniae & CCC 110-07 & Glycine $\max$ & Argentina, Inriville, Córdoba & 15 (TU-a), 24 (TU-c) & 2007 \\
\hline 46135 & Fusarium tucumaniae & CCC 111-07 & Glycine $\max$ & Argentina, Inriville, Córdoba & 13 (TU-a), 18 (TU-c) & 2007 \\
\hline 46136 & Fusarium tucumaniae & CCC 112-07 & Glycine $\max$ & Argentina, Inriville, Córdoba & $8(\mathrm{TU}-\mathrm{a}), 10(\mathrm{TU}-\mathrm{c})$ & 2007 \\
\hline 46138 & Fusarium tucumaniae & CCC 114-07 & Glycine $\max$ & Argentina, Leones, Córdoba & 13 (TU-a), 18 (TU-c) & 2007 \\
\hline 46139 & Fusarium tucumaniae & CCC $115-07$ & Glycine $\max$ & Argentina, Leones, Córdoba & $7(\mathrm{TU}-\mathrm{c})$ & 2007 \\
\hline 46140 & Fusarium tucumaniae & CCC 166-07 & Glycine $\max$ & Argentina, Casilda, Santa Fe & 8 (TU-a), 12 (TU-c) & 2007 \\
\hline 46141 & Fusarium tucumaniae & CCC 154-07 & Glycine $\max$ & Argentina, Casilda, Santa Fe & 6 (TU-a), 12 (TU-c) & 2007 \\
\hline 46142 & Fusarium tucumaniae & CCC $155-07$ & Glycine max & Argentina, Casilda, Santa Fe & 12 (TU-c) & 2007 \\
\hline 46143 & Fusarium tucumaniae & CCC 164-07 & Glycine $\max$ & Argentina, Pilar, Buenos Aires & 8 (TU-a), 13 (TU-c) & 2007 \\
\hline 46144 & Fusarium tucumaniae & CCC $163-07$ & Glycine $\max$ & Argentina, Pilar, Buenos Aires & 8 (TU-a), 12 (TU-c) & 2007 \\
\hline 46146 & Fusarium tucumaniae & CCC 153-07 & Glycine $\max$ & Argentina, Pilar, Buenos Aires & 8 (TU-a), 12 (TU-c) & 2007 \\
\hline 46147 & Fusarium tucumaniae & CCC 157-07 & Glycine $\max$ & Argentina, Pilar, Buenos Aires & 7 (TU-a), 10 (TU-c) & 2007 \\
\hline 46148 & Fusarium tucumaniae & CCC $138-07$ & Glycine $\max$ & Argentina, Tucumán & 7 (TU-a), 8 (TU-C) & 2007 \\
\hline 46149 & Fusarium tucumaniae & CCC 133-07 & Glycine $\max$ & Argentina, Tucumán & 8 (TU-a), 8 (TU-c) & 2007 \\
\hline
\end{tabular}


used in the extension reactions for the MLGT assay, together with three positive control probes to confirm the presence of the these three templates in the multiplex ASPE reaction, and 12 speciesspecific probes. Reactions were performed in a total volume of 20 $\mu$ that included $1 \times$ PCR buffer, $1.25 \mathrm{mM} \mathrm{MgCl}_{2}, 5 \mu \mathrm{M}$ dATP, dGTP, dTTP, $5 \mu \mathrm{M}$ biotin-dCTP, $0.75 \mathrm{U}$ of Platinum GenoTYPE Tsp DNA polymerase (Invitrogen Life Technologies), $25 \mathrm{nM}$ of each probe primer, and $5 \mu \mathrm{l}$ of purified amplicon $(\approx 0.2 \mu \mathrm{g})$. ASPE reactions were run for $120 \mathrm{~s}$ at $96^{\circ} \mathrm{C}$, followed by 40 cycles of $30 \mathrm{~s}$ at $94^{\circ} \mathrm{C}, 60 \mathrm{~s}$ at $55^{\circ} \mathrm{C}, 120 \mathrm{~s}$ at $74^{\circ} \mathrm{C}$, and ending in a $4^{\circ} \mathrm{C}$ soak. Hybridization and detection followed published protocols (25). Given that the 24-bp tag sequence on the $5^{\prime}$ end of each ASPE product hybridizes to a specific antitag attached to a microsphere with a unique spectral address, it was possible to sort and evaluate the extension products from the different probes individually using a Luminex 100 flow cytometer. Indices of discrimination (ID) for the MLGT identifications were determined by first subtracting the average intensity of three water controls from each value, then dividing the minimum fluorescence intensity (MFI) by the maximum nontarget fluorescence intensity.

\section{RESULTS}

Molecular phylogenetics. Nucleotide sequence data were obtained from portions of three loci to investigate species limits within the SDS-BRR clade. Aligned DNA sequences from the $E F-1 a$ gene (687 bp), anonymous intergenic locus 96 (1,520 bp), and the nuclear ribosomal IGS rDNA $(2,765 \mathrm{bp})$ were analyzed individually and as a combined data set (Fig. 1) (4,972 bp) via MP as implemented in PAUP (42). Four soybean SDS (i.e., $F$. tucumaniae, F. brasiliense, F. virguliforme, and Fusarium sp.) and two BRR (i.e., F. phaseoli and F. cuneirostrum) pathogens were resolved as genealogically exclusive, phylogenetically distinct species in MP bootstrap analyses of the IGS rDNA and combined data set. Analyses of the partial EF-1a gene and locus 96 data partitions resolved $F$. brasiliense, $F$. virguliforme, and Fusarium sp. as reciprocally monophyletic. Relationships between the three other SDS-BRR clade species were unresolved in analyses of the latter two loci. Previously, Fusarium sp. and F. cuneirostrum were treated as conspecific because the monophyly of the former species could not be assessed, given that it was represented by a single isolate from Brazil (4). However, with the inclusion of a second isolate of this Fusarium sp. (Fig. 1; NRRL 36877 from Santa Fe, Argentina), the present analyses indicate that it and $F$. cuneirostrum are reciprocally monophyletic sisters. Even though the six species within the SDS-BRR clade are closely related phylogenetically, it is noteworthy that they are all phenotypically distinct $(3,4)$. Concordant results (not shown) were obtained under the maximum likelihood criterion using the general timereversible model of nucleotide substitution with a proportion of invariant sites and gamma-distributed rate heterogeneity in GARLI (50).

Assessment of published SDS and BRR species-specific primers and probes. Based on our improved understanding of species boundaries within the SDS-BRR clade, we conducted nucleotide sequence comparisons of the three loci used in the design of published SDS and BRR species-specific PCR primers and probes to determine whether they could differentiate the newly delimited SDS and BRR pathogens. Comparative DNA sequence analyses of partial gene sequences of the mtSSU rDNA (8,14-16), EF-la gene $(7,14)$, and ITS + 28S rDNA (22) of the SDS and BRR pathogens revealed that highly conserved regions of these three loci were used in the design of the assays. Therefore none of these assays are species-specific based on our current understanding of species limits within the SDS-BRR clade.

Design and validation of the allele-specific genotyping assay. Given the inability of published molecular diagnostics to differentiate the fusaria associated with SDS and BRR, multilocus DNA sequence data from the 65-isolate design panel (DP) (Fig. 1) was used to design probes for MLGT analysis of the SDS and BRR fusaria (Table 3). This panel included 12 species-specific probes and three positive control probes to confirm the successful amplification of the IGS rDNA and locus 51 and 96 amplicons in the ASPE reaction. Probe performance data for the DP are provided in Table 1. ID values for the 12 MLGT probes ranged from 3 to 44 which means that MFI values for isolates with a negative genotype were less than one-third the MFI values for strains with a positive genotype. Sequences in the primer annealing sites independently confirmed that the MLGT assay should accurately identify all 65 isolates in the DP (Table 1).

MLGT of experimental panel. The validated microsphere array successfully identified 205 soybean SDS isolates in the EP.

TABLE 2. (Continued from preceeding page)

\begin{tabular}{|c|c|c|c|c|c|c|}
\hline $\mathrm{NRRL}^{\mathrm{a}}$ & Species & Equivalent no. ${ }^{\mathrm{b}}$ & Host & Origin & $\begin{array}{c}\text { Index of } \\
\text { discrimination }^{\mathrm{c}}\end{array}$ & $\begin{array}{c}\text { Year } \\
\text { isolated }\end{array}$ \\
\hline 46150 & Fusarium tucumaniae & CCC 158-07 & Glycine $\max$ & Argentina, Tucumán & 7 (TU-a), 12 (TU-c) & 2007 \\
\hline 46151 & Fusarium tucumaniae & CCC 152-07 & Glycine $\max$ & Argentina, La Cocha, Tucumán & 8 (TU-a), 11 (TU-c) & 2007 \\
\hline 46152 & Fusarium tucumaniae & CCC 159-07 & Glycine max & Argentina, La Cocha, Tucumán & 8 (TU-a), 8 (TU-C) & 2007 \\
\hline 46154 & Fusarium tucumaniae & CCC 137-07 & Glycine max & Argentina, La Cocha, Tucumán & 6 (TU-a), 6 (TU-C) & 2007 \\
\hline 46155 & Fusarium tucumaniae & CCC 132-07 & Glycine $\max$ & Argentina, La Cocha, Tucumán & 7 (TU-a), 12 (TU-c) & 2007 \\
\hline 46157 & Fusarium tucumaniae & $07-620-2$ & Glycine max & Argentina, La Virginia Burruyacú, Tucumán & 7 (TU-a), 11 (TU-c) & 2007 \\
\hline 46158 & Fusarium tucumaniae & CCC 149-07 & Glycine $\max$ & Argentina, La Virginia Burruyacú, Tucumán & $5(\mathrm{TU}-\mathrm{c})$ & 2007 \\
\hline 46160 & Fusarium tucumaniae & CCC 136-07 & Glycine $\max$ & Argentina, Leones, Córdoba & $12(\mathrm{TU}-\mathrm{c})$ & 2007 \\
\hline 46161 & Fusarium tucumaniae & CCC 149-07 & Glycine $\max$ & Argentina, Marcos Juarez, Córdoba & 9 (TU-a), 13 (TU-c) & 2007 \\
\hline 46162 & Fusarium tucumaniae & CCC 136-07 & Glycine $\max$ & Argentina, Marcos Juarez, Córdoba & 9 (TU-a), 12 (TU-c) & 2007 \\
\hline 46163 & Fusarium tucumaniae & CCC 172-07I & Glycine max & Argentina, Marcos Juarez, Córdoba & 8 (TU-a), 12 (TU-c) & 2007 \\
\hline 46165 & Fusarium tucumaniae & CCC 151-07 & Glycine $\max$ & Argentina, Marcos Juárez, Córdoba & 6 (TU-a), 7 (TU-C) & 2007 \\
\hline 46166 & Fusarium tucumaniae & CCC 162-07 & Glycine max & Argentina, Inriville, Córdoba & 7 (TU-a), 9 (TU-C) & 2007 \\
\hline 46167 & Fusarium tucumaniae & CCC $165-07$ & Glycine $\max$ & Argentina, Inriville, Córdoba & 8 (TU-a), 9 (TU-C) & 2007 \\
\hline 46168 & Fusarium tucumaniae & CCC 173-07 & Glycine $\max$ & Argentina, Inriville, Córdoba & 7 (TU-c) & 2007 \\
\hline 46169 & Fusarium tucumaniae & CCC 161-07 & Glycine $\max$ & Argentina, Tucumán & 9 (TU-a), 9 (TU-c) & 2007 \\
\hline 46170 & Fusarium sp. & CCC 169-07 & Glycine max & Argentina, Las Lajitas, Salta & 39 (CR-a), 10 (CR-b) & 2007 \\
\hline 46171 & Fusarium sp. & CCC 168-07 & Glycine $\max$ & Argentina, Las Lajitas, Salta & 32 (CR-a), 7 (CR-b) & 2007 \\
\hline 46172 & Fusarium sp. & $07-664-3$ & Glycine $\max$ & Argentina, Las Lajitas, Salta & 22 (CR-a), 5 (CR-b) & 2007 \\
\hline 46173 & Fusarium sp. & CCC 174-07 & Glycine max & Argentina, Las Lajitas, Salta & 34 (CR-a), 10 (CR-b) & 2007 \\
\hline 46174 & Fusarium sp. & CCC 175-07 & Glycine $\max$ & Argentina, Las Lajitas, Salta & 37 (CR-a), 9 (CR-b) & 2007 \\
\hline 46175 & Fusarium sp. & CCC 176-07 & Glycine max & Argentina, Las Lajitas, Salta & 37 (CR-a), 9 (CR-b) & 2007 \\
\hline 46177 & Fusarium tucumaniae & CCC 178-07 & Glycine $\max$ & Argentina, Entre Ríos & $8(\mathrm{TU}-\mathrm{c})$ & 2007 \\
\hline 46178 & Fusarium tucumaniae & CCC 177-07 & Glycine max & Argentina, Entre Ríos & $14(\mathrm{TU}-\mathrm{c})$ & 2007 \\
\hline 46179 & Fusarium tucumaniae & CCC 171-07 & Glycine $\max$ & Argentina, Entre Ríos & 8 (TU-c) & 2007 \\
\hline
\end{tabular}


Probe performance data for the EP are provided in Table 2. ID values for the species probes ranged from 3 to 56, meaning the MFI values for isolates with a positive genotype were at least 3 times greater than the MFI values for strains with a negative genotype. Combined analysis of the DP and $\mathrm{EP}(N=271)$ provide an initial estimate of soybean SDS species diversity in Argentina and the United States. Results of the present study revealed that $F$. tucumaniae is the predominant SDS pathogen in five of the six Argentine provinces surveyed, comprising $87.2 \%$ of the SDS isolates recovered. The Argentinean province of Salta is the only exception in that the undescribed Fusarium sp., formerly thought to be conspecific with the BRR pathogen $F$. cuneirostrum (4), accounted for all six SDS isolates recovered in this province (Fig. $3)$. The present survey revealed that three other SDS pathogens are present in Argentina, but in low frequencies ( $F$. virguliforme $7.5 \%$, Fusarium sp. $4.8 \%$, and $F$. brasiliense $0.5 \%$ ). In addition, limited sampling within five Brazilian districts revealed that three of the four soybean SDS pathogens are present in Brazil (Fig. 3). By way of contrast, surveys of eight major soybean-growing states suggests that a highly clonal population of $F$. virguliforme appears to be responsible for all soybean SDS within the United States $(3,29,43)$, with the exception of a single isolate of $F$. brasiliense from California (Tables 1 and 2).

\section{DISCUSSION}

The present study extends our knowledge of species boundaries within the SDS-BRR clade by the discovery of a fourth SDS species, Fusarium sp., which is currently only known from the District of Goiás in Brazil (NRRL 31949) and the northern provinces of Salta, Tucumán, and Santa Fe in Argentina (Tables 1 and 2). Previously, this soybean SDS species was tentatively considered a divergent isolate of the BRR pathogen $F$. cuneirostrum because it was represented by a single isolate (NRRL 31949), and because it formed a clade with the latter species (4). However, with the discovery of additional isolates of this species from Argentina, multilocus bootstrap analyses of the three individual and combined gene partitions demonstrated that $F$. cuneirostrum and Fusarium sp. represent genealogically exclusive, reciprocally monophyletic sister taxa. Even though isolates of $F$. cuneirostrum from the United States, Canada, and Japan share the same 3-locus haplotype (Fig. 1), electrophoretic karyotypes of this species from Japan (NRRL 22276 and 31104) are polymorphic (41), suggesting that genome organization within this species is variable. Moreover, isolates of $F$. brasiliense (NRRL 22678 and 22743) and $F$. cuneirostrum (NRRL 22158) appear to possess the same unique mtSSU rDNA RFLP haplotype (32), indicating that this locus is too conserved to differentiate these species.

Application of the forma specialis naming system for the SDS and BRR pathogens (i.e., f. sp. glycines and f. sp. phaseoli), and for other phytopathogens within the FSSC $(20,26,49)$ and $F$. oxysporum species complex (23), obscures the genetic diversity, phylogenetic relationships, geographic distribution, and host range of these pathogens. Based on the discovery of four SDS and two BRR pathogens $(3,4$; present study), in the absence of detailed phenotypic or molecular systematic data, it is impossible to conclude with certainty what soybean SDS pathogens were studied when they are reported as $F$. solani f. sp. glycines, $F$. solani $\mathrm{f}$. sp. phaseoli, or F. solani. Furthermore, even though the six SDS and BRR species form a genealogically exclusive subclade within the putatively South American clade 2 of the FSSC (20), the molecular phylogenetic results indicate that evolution of host specificity is homoplastic in that these two formae speciales exhibit a paraphyletic set of relationships. The available data suggests that pathogenicity to soybean may represent the plesiomorphic condition, given that the SDS pathogen $F$. virguliforme appears to represent the most basal divergence within the SDS-BRR clade (4). Because soybean was introduced to South and North America

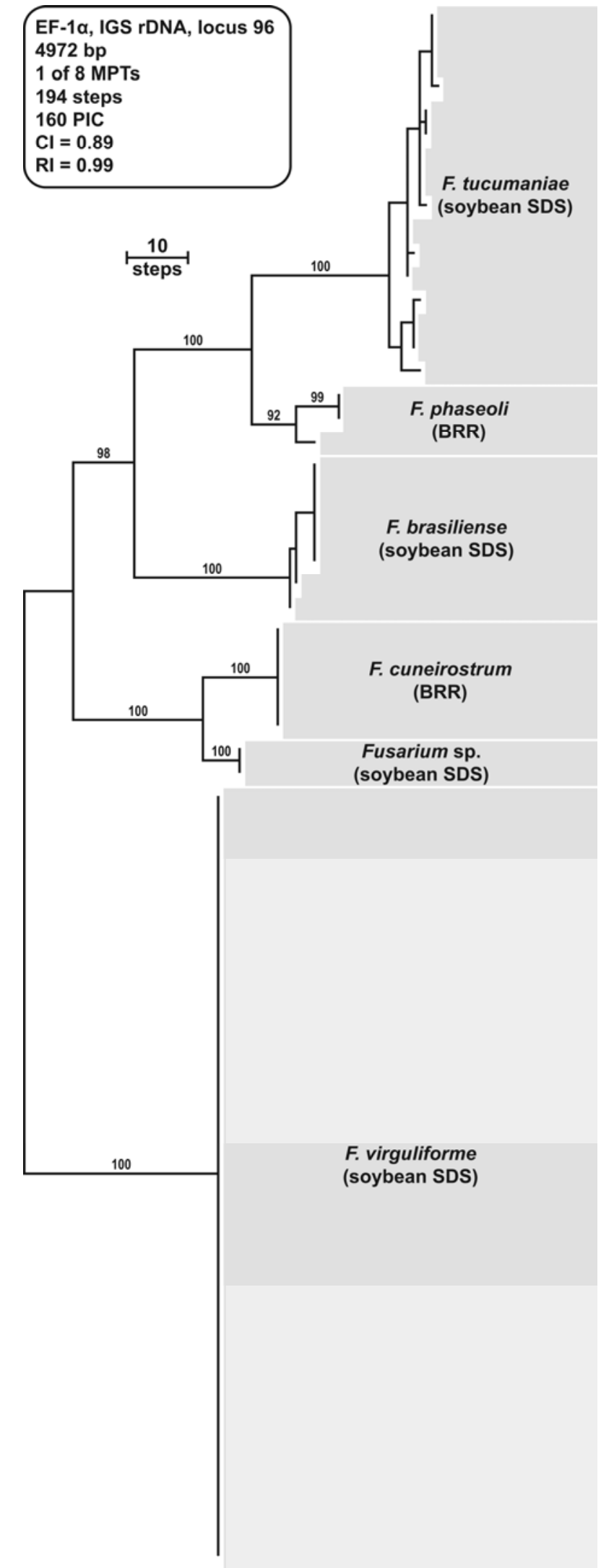

Fig. 1. One of eight most-parsimonious trees inferred from DNA sequence data from portions of three loci ( $E F-1 a$, intergenic spacer region [IGS] rDNA, and locus 96) from 58 soybean sudden death syndrome (SDS) and 8 bean root rot (BRR) pathogens. Sequences of Fusarium virguliforme were used to root the phylogeny based on more inclusive analyses $(3,4)$. Numbers above nodes represent maximum parsimony (MP) bootstrap support $>90 \%$ from 1,000 pseudoreplicates of the data. Note that the soybean SDS and BRR pathogens exhibit a paraphyletic set of relationships. PIC, parsimony informative character; CI, consistency index; RI, retention index. 
approximately one and two centuries ago, respectively, and the available data strongly support a South or Mesoamerican origin of the SDS-BRR pathogens, we theorize that the SDS fusaria jumped from some unknown host(s) to soybean after the relatively recent introduction of this Asian species to the New World (38). Given the very close and paraphyletic relationship of the SDS and BRR fusaria, it seems plausible that one or more of these species may have evolved in one or more of the three centers of diversity of wild Phaseolus species in Mexico, Ecuador, or Argentina $(29,37)$. It should be possible to test whether one or more of these regions are the source of origin of these pathogens by analyzing haplotype and nucleotide diversity of isolates collected from wild Phaseolus populations in these regions (9). Such an investigation may also improve our understanding of their population structure
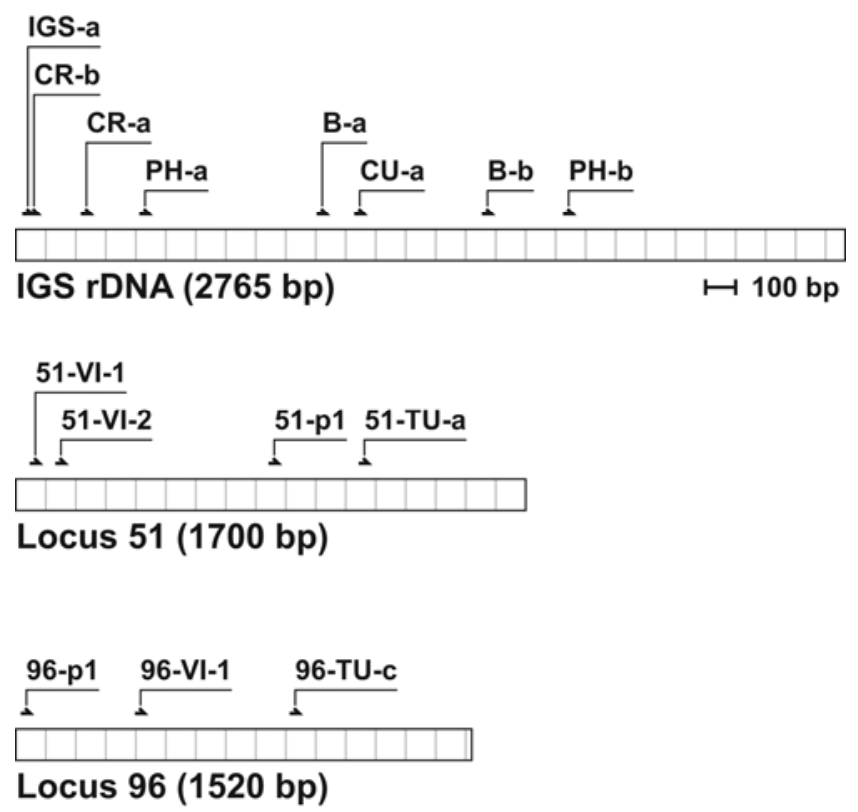

Fig. 2. Location of 12 species-specific and three positive control forward primers used in the soybean sudden death syndrome and bean root rot multiplex genotyping assay. Note that eight probe primers prime on the intergenic spacer region rDNA, four on locus 51, and three on locus 96 . and reproductive mode. Of the six SDS-BRR species discovered to date, only $F$. tucumaniae has been shown to possess high levels of genetic variability, suggesting sexual recombination in the field $(3,4)$. A hypothesized sexual cycle was subsequently confirmed in this species employing heterothallic crosses in the laboratory (6). By comparison, three of the six SDS-BRR species may be strictly clonal on soybean or Phaseolus and mung bean, based on multilocus phylogenetics and analyses of other molecular markers $(2,6,16,32)$.

As discussed previously (6), we strongly advocate using only the fusarial anamorph name, even for species with a known sexual state such as $F$. tucumaniae, to avoid confusion associated with duplicity of names for a single species and because several teleomorph names have recently been used for members of the FSSC (i.e., Hypomyces, Nectria, Neocosmospora, and Haematonectria) (20,30). Molecular phylogenetic analyses have demonstrated that Nectria sensu lato is a paraphyletic grade, and that this generic name should be restricted to members of the monophyletic $N$. cinnabarina species group (36). It is worth noting that the name Haematonectria has been applied to a paraphyletic group of fusaria within which Neocosmospora forms a distinct lineage $(20,26,30)$, providing two unsatisfactory options: recognizing a paraphyletic taxon that is also a later synonym of Neocosmospora according to the botanical code's principle of priority, or broadening the concept of Neocosmospora, the earliest available legitimate generic name, far beyond its original circumscription (20). Fusaria in the SDS-BRR clade are unique within the FSSC in that all of the species except the SDS pathogen Fusarium sp. have been formally described with Latin binomials $(3,4)$, and the latter species is currently being formally described (T. Aoki, unpublished data). Unfortunately, even two-thirds of a century after Snyder and Hansen (39) circumscribed the overly broadly defined species F. solani $(13,19)$, most of the species within the FSSC are still reported in the phytopathological and clinical microbiology literature under this name. Several independent multilocus molecular phylogenetic analyses, however, have clearly demonstrated that the FSSC comprises at least 47 phylogenetically distinct species distributed among three strongly supported clades $(20,26$, 40,49). Although morphological apomorphies have yet to be identified for most of the species within the FSSC, a robust multilocus species and haplotype nomenclature has been proposed for all of the members of clade 3 , which comprises most of the eco-

TABLE 3. Allele-specific and positive control probe primers used in the genotyping assay

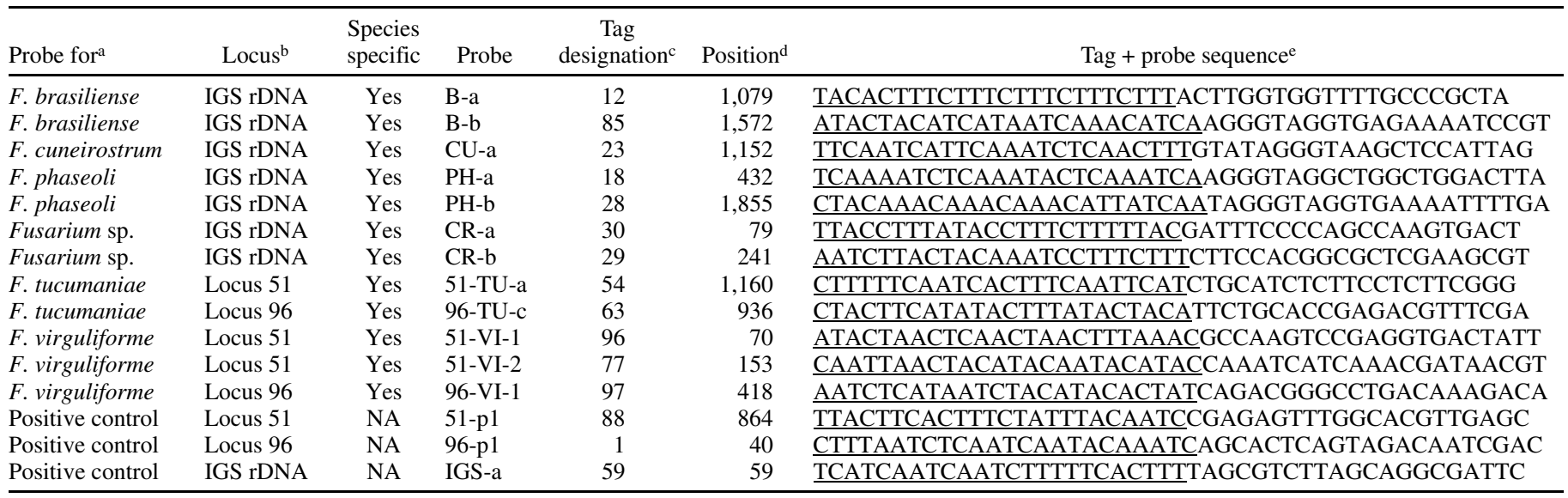

${ }^{a}$ Species or positive control for polymerase chain reaction (PCR) amplification of locus 51, locus 96, or the intergenic spacer (IGS) rDNA.

${ }^{\mathrm{b}}$ Two anonymous loci, designated 51 and 96 , and the IGS rDNA were targeted in the allele-specific assay.

${ }^{c}$ A unique number between 1 and 100 was assigned at the Luminex Corporation website for each tag sequence.

d $3^{\prime}$-Most nucleotide position of probe primer in the sequence alignment of the respective locus targeted.

e The unique tag sequence (underlined) attached to the $5^{\prime}$ end of each probe sequence was assigned at the Luminex Corporation website. Each tag is designed to hybridize to the antitag attached to only 1 of the 15 different fluorescent microspheres used in the assay. The $3^{\prime}$-most nucleotide of each probe sequence is specific for one of the four sudden death syndrome pathogens, or was used as a positive control for the PCR amplification of the loci targeted in the allelespecific assay. 
nomically important phytopathogens and all of the medically important species within the FSSC $(26,49)$.

Results of the present study, and our parallel studies on the genetic diversity and mycotoxin potential of the FHB pathogens $(24,27,28,46,48)$, highlight the importance of rigorously identifying species limits, based on reciprocal monophyly at multiple loci (i.e., GCPSR [43]), rather than relying on a homoplasious character such as host specificity to delimit taxa (44). Through comparative DNA sequence analyses, we have determined that published PCR primer pairs and probes for the detection and identification of the SDS and BRR pathogens prime on highly conserved regions of the three loci used in the design of these molecular diagnostic assays (ITS - 28S rDNA [22]; mtSSU rDNA [8,14-16]; and $E F-1 a[7,14])$. Given the inability of the published molecular assays to differentiate the fusaria associated with SDS and BRR, incorporation of these diagnostics in pathogen surveillance programs could have serious negative consequences for crop biosecurity because the center of origin of these six pathogens is theorized to be outside the United States. As such, the available DNA-based pathogen detection systems are unable to distinguish, for example, between foreign soybean SDS pathogens that already have entered the United States (i.e., $F$. virguliforme and $F$. brasiliense) and the most important soybean SDS pathogen in South America (i.e., F. tucumaniae [3,4,33; present study]). The latter species, unlike the highly clonal population of $F$. virguliforme on soybean in North and South America, possesses a sexual cycle and concomitant high levels of genetic diversity on soybean in Argentina and Brazil. Because resistance to soybean SDS is quantitative, a sexually recombining pathogen such as F. tucumaniae, in theory, is much more likely to

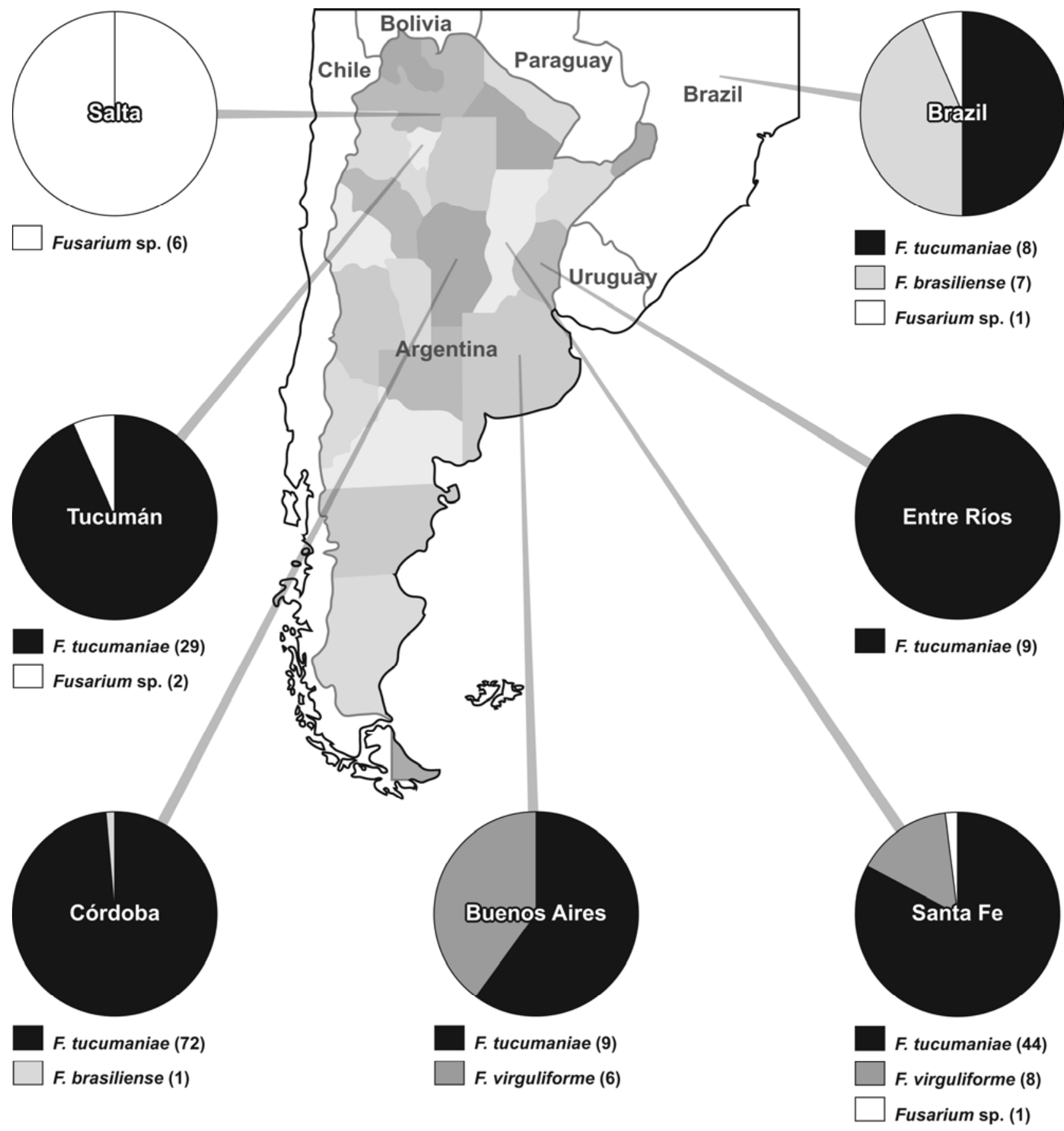

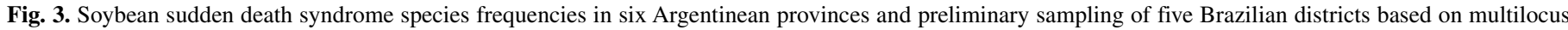

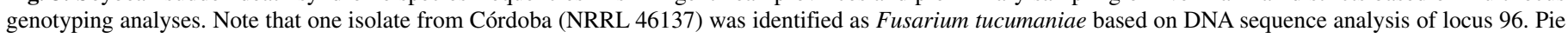
charts show the species composition in each area. 
overcome host resistance, which may help explain why it is the dominant SDS pathogen in South America. Moreover, given the close relationship of the SDS and BRR pathogens and the fact they colonize some of the same hosts, the potential for interspecific hybrids with novel pathogenicity traits poses an additional threat to the production of soybean and dry edible bean. These findings highlight the need to not only expand our arsenal of soybean SDS species-specific diagnostics, but to also develop diagnostics for distinguishing the mating types idiomorphs so as to minimize the significant threat poised by a sexually recombining SDS pathogen to soybean production within the United States and elsewhere. Given that only 15 probe primers were used in the MLGT assay, and up to 100 can be accommodated in the single-well microsphere array, it should be relatively easy to expand the current assay to accommodate newly discovered genetic variation within known and novel soybean SDS and BRR pathogens, and even include probes for nonfungal pathogens such as the soybean cyst nematode (Heterodera glycines) if needed. Because the probe primers were designed based on known species-specific DNA sequence variation, updating the assay as novel diversity is discovered can be done easily as evidenced by our continuous updating of the MLGT array for FHB species and trichothecene toxin potential determination $(27,46,48)$. Though beyond the scope of the present study, methods are available which should make it possible to analyze complex DNA samples from field samples using the MLGT assay $(11,12)$, thereby obviating the time-consuming step of culturing the notoriously slow growing SDS and BRR fusaria. Even though the Luminex system is ideally suited for distinguishing multiple pathogens in a single-well assay, the multilocus sequence data could be used to design a species-specific primer pair for detection of any one of the soybean SDS and BRR fusaria now that their species limits have been clearly resolved. Although DNA sequence data from the IGS rDNA can be used to accurately identify all of the SDS-BRR fusaria, sequencing is much more time-consuming, labor-intensive, and more expensive than using the high-throughput MLGT assay which can identify 96 samples in 1 to $2 \mathrm{~h}$.

Results of the present study add to the growing repertoire of DNA arrays for the detection and identification of agriculturally $(11,12,46)$ and medically important fusaria $(25)$. We designed and validated the MLGT assay for differentiating the six SDS and BRR pathogens only after species limits were delimited using GCPSR (43). Independent identifications of the 65-isolate design panel using a 3-locus MLST scheme and the MLGT assay both yielded species identifications with $100 \%$ accuracy. However, isolate NRRL 46137 from Córdoba, Argentina in the EP, identified as $F$. tucumaniae, based on sequence analysis of locus 96, was not subjected to the MLGT analysis due to repeated failed attempts to generate a multiplex PCR. We attribute this result to poor quality DNA. It is worth noting that none of the MLGT species probes gave false positives.

Our MLGT analyses provide a preliminary estimate of soybean SDS species diversity in the United States $(N=64)$, Argentina $(N=187)$ and Brazil $(N=16)$, revealing that $F$. tucumaniae and $F$. virguliforme are the dominant SDS pathogens in South and North America, respectively. Although several surveys suggest that virtually all soybean SDS is caused by $F$. virguliforme within the United States $(2,16,32,47)$, this pathogen was found in only two of the six provinces we surveyed in Argentina, and then only in very low frequencies compared to $F$. tucumaniae. In addition, $F$. virguliforme has not been detected in Brazil based on very limited sampling (5; present study). These results punctuate the need for additional pathogen surveys to identify the center of origin(s) of soybean SDS in South or Mesoamerica. In summary, the MLGT assay provides agricultural scientists with a unique molecular diagnostic for surveillance and identification of the soybean SDS and BRR pathogens (34). With the development and validation of this assay, it is now possible to monitor changes in soybean SDS and BRR species composition in South and North America over time. Furthermore, this assay should assist plant inspection and quarantine officials in their efforts to prevent these economically destructive pathogens from being spread into additional nonindigenous areas.

\section{ACKNOWLEDGMENTS}

We thank T. J. Ward and T. Usgaard for detailed advice on designing and running the MLGT assay, J. Ness for collecting the DNA sequence data, and D. Fraser for preparing the figures. The mention of firm names or trade products does not imply that they are endorsed or recommended by the U.S. Department of Agriculture over other firms or similar products not mentioned.

\section{LITERATURE CITED}

1. Abney, T. S., Richards, T. L., and Roy, K. W. 1993. Fusarium solani from ascospores of Nectria haematococca causes sudden death syndrome of soybean. Mycologia 85:801-806.

2. Achenbach, L. A., Patrick, J., and Gray, L. 1996. Use of RAPD markers as a diagnostic tool for the identification of Fusarium solani isolates that cause soybean sudden death syndrome. Plant Dis. 80:1228-1232.

3. Aoki, T., O’Donnell, K., Homma, Y., and Lattanzi, A. R. 2003. Suddendeath syndrome of soybean is caused by two morphologically and phylogenetically distinct species within the Fusarium solani species complex $-F$. virguliforme in North America and F. tucumaniae in South America. Mycologia 95:660-684.

4. Aoki, T., O'Donnell, K., and Scandiani, M. M. 2005. Sudden death syndrome of soybean in South America is caused by four species of Fusarium: Fusarium brasiliense sp. nov., F. cuneirostrum sp. nov., F. tucumaniae, and F. virguliforme. Mycoscience 46:162-183.

5. Arruda, G. M. T., Miller, R. N. G., Ferreira, M. A. S. V., and Café-Filho, A. C. 2005. Morphological and molecular characterization of the suddendeath syndrome pathogen of soybean in Brazil. Plant Pathol. 54:53-65.

6. Covert, S. F., Aoki, T., O'Donnell, K., Starkey, D., Holliday, A., Geiser, D. M., Cheung, F., Town, C., Strom, A., Juba, J., Scandiani, M., and Yang, X. B. 2007. Sexual reproduction in the sudden death syndrome pathogen Fusarium tucumaniae. Fungal Genet. Biol. 44:799-807.

7. Filion, M., St.-Arnaud, M., and Jabaji-Hare, S. H. 2003. Quantification of Fusarium solani f. sp. phaseoli in mycorrhizal bean plants and surrounding mycorrhizosphere soil using real-time polymerase chain reaction and direct isolations on selective media. Phytopathology 93:229235.

8. Gao, X., Jackson, T. A., Lambert, K. N., Li, S., Hartman, G. L., and Niblack, T. L. 2004. Detection and quantification of Fusarium solani f. sp. glycines in soybean roots with real-time quantitative polymerase chain reaction. Phytopathology 88:1372-1380.

9. Gómez-Alpizar, L., Carbone, I., and Ristaino, J. B. 2007. An Andean origin of Phytophthora infestans inferred from mitochondrial and nuclear gene genealogies. Proc. Natl. Acad. Sci. USA 104:3306-3311.

10. Kang, S., Blair, J. E., Geiser, D. M., Khang, C.-H., Park, S.-Y., Gahegan, M., O’Donnell, K., Luster, D. G., Kim, S.-H., Ivors, K. L., Lee, Y.-H., Lee, Y.-W., Grünwald, N. J., Martin, F. M., Coffey, M. D., Veeraraghavan, N., and Makalowska, I. 2007. Plant pathogen culture collections: It takes a village to preserve these resources vital to the advancement of agricultural security and plant pathology. Phytopathology 96:920-925.

11. Kristensen, R., Berdal, K. G., and Holst-Jensen, A. 2006. Simultaneous detection and identification of trichothecene- and moniliformin-producing Fusarium species based on multiplex SNP analysis. J. Appl. Microbiol. 102:1071-1081.

12. Kristensen, R., Gauthier, G., Berdal, K. G., Hamels, S., Remacle, J., and Holst-Jensen, A. 2006. DNA microarray to detect and identify trichothecene- and moniliformin-producing Fusarium species. J. Appl. Microbiol. 102:1060-1070.

13. Leslie, J. F., and Summerell, B. 2006. The Fusarium Laboratory Manual. Blackwell Publishing, Ames, IA.

14. Li, S., and Hartman, G. L. 2003. Molecular detection of Fusarium solani f. sp. glycines in soybean roots and soil. Plant Pathol. 52:74-83.

15. Li, S., Hartman, G. L., Domier, L. L., and Boykin, D. 2008. Quantification of Fusarium solani f. sp. glycines isolates in soybean roots by colony-forming unit assays and real-time quantitative PCR. Theor. Appl. Genet. 117:343-352

16. Li, S., Tam, Y. K., and Hartman, G. L. 2000. Molecular differentiation of Fusarium solani f. sp. glycines from other $F$. solani based on mitochondrial small subunit rDNA sequences. Phytopathology 90:491-497. 
17. Maddison, W. P., and Maddison, D. R. 2002. MacClade 4. Analysis of Phylogeny and Evolution, version 4.06. Sinauer Associates, Sunderland, MA.

18. Matuo, T., and Snyder, W. C. 1973. Use of morphology and mating populations in the identification of formae speciales in Fusarium solani. Phytopathology 63:562-565.

19. Nelson, P. E., Toussoun, T. A., and Marasas, W. F. O. 1983. Fusarium Species: An Illustrated Manual for Identification. Pennsylvania State University Press, University Park, PA.

20. O'Donnell, K. 2000. Molecular phylogeny of the Nectria haematococcaFusarium solani species complex. Mycologia 92:919-938.

21. O’Donnell, K., Cigelnik, E., and Nirenberg, H. 1998. Molecular systematics and phylogeography of the Gibberella fujikuroi species complex. Mycologia 90:465-493.

22. O'Donnell, K., and Gray, L. E. 1995. Phylogenetic relationships of the soybean sudden death syndrome pathogen Fusarium solani f. sp. phaseoli inferred from rDNA sequence data and PCR primers for its identification. Mol. Plant-Microbe Interact. 8:709-716.

23. O’Donnell, K., Kistler, H. C., Cigelnik, E., and Ploetz, R. C. 1998. Multiple evolutionary origins of the fungus causing Panama disease of banana: Concordant evidence from nuclear and mitochondrial gene genealogies. Proc. Natl. Acad. Sci. USA 95:2044-2049.

24. O'Donnell, K., Kistler, H. C., Tacke, B. K., and Casper, H. H. 2000. Gene genealogies reveal global phylogeographic structure and reproductive isolation among lineages of Fusarium graminearum, the fungus causing wheat scab. Proc. Nat. Acad. Sci. USA 97:7905-7910.

25. O'Donnell, K., Sarver, B. A. J., Brandt, M., Chang, D. C., Noble-Wang, J., Park, B. J., Sutton, D. A., Benjamin, L., Lindsley, M., Padhye, A., Geiser, D. M., and Ward, T. J. 2007. Phylogenetic diversity and microsphere array-based genotyping of human pathogenic fusaria, including isolates from the multistate contact lens-associated U.S. keratitis outbreaks of 2005 and 2006. J. Clin. Microbiol. 45:2235-2248.

26. O’Donnell, K., Sutton, D. A., Fothergill, A., McCarthy, D., Rinaldi, M. G., Brandt, M. E., Zhang, N., and Geiser, D. M. 2008. Molecular phylogenetic diversity, multilocus haplotype nomenclature, and in vitro antifungal resistance within the Fusarium solani species complex. J. Clin. Microbiol. 46:2477-2490.

27. O’Donnell, K., Ward, T. J., Aberra, D., Kistler, H. C., Aoki, T., Orwig, N., Kimura, M., Bjørnstad, Å., and Klemsdal, S. S. 2008. Multilocus genotyping and molecular phylogenetics resolve a novel head blight pathogen within the Fusarium graminearum species complex from Ethiopia. Fungal Genet. Biol. 45:1514-1522.

28. O'Donnell, K., Ward, T. J., Geiser, D. M., Kistler, H. C., and Aoki, T. 2004. Genealogical concordance between the mating type locus and seven other nuclear genes supports formal recognition of nine phylogenetically distinct species within the Fusarium graminearum clade. Fungal Genet. Biol. 41:600-623.

29. Pickersgill, B. 2007. Domestication of plants in the Americas: Insights from Mendelian and molecular genetics. Ann. Bot. 100:925-940.

30. Rossman, A. Y., Samuels, G. J., Rogerson, C. T., and Lowen, R. 1999. Genera of Bionectriaceae, Hypocreaceae and Nectriaceae (Hypocreales, Ascomycetes). Stud. Mycol. 42:1-248.

31. Roy, K. W., Rupe, J. C., Hershman, D. E., and Abney, T. S. 1997. Sudden death syndrome of soybean. Plant Dis. 81:1100-1111.

32. Rupe, J. C., Correll, J. C., Guerber, J. C., Becton, C. M., Gbur, E. E., Cummings, M. S., and Yount, P. A. 2001. Differentiation of the sudden death syndrome pathogen of soybean, Fusarium solani f. sp. glycines, from other isolates of $F$. solani based on cultural morphology, pathogenicity, and mitochondrial DNA restriction fragment length polymorphisms. Can. J. Bot. 79:829-835.

33. Scandiani, M., Ruberti, D., O’Donnell, K., Aoki, T., Pioli, R., Giorda, L., Luque, A., and Biasoli, M. 2004. Recent outbreak of soybean sudden death syndrome caused by Fusarium virguliforme and $F$. tucumaniae in Argentina. Plant Dis. 88:1044.

34. Schaad, N. W., Frederick, R. D., Shaw, J., Schneider, M. L., Hickson, R., Petrillo, M. D., and Luster, D. G. 2003. Advances in molecular-based diagnostics in meeting crop biosecurity and phytosanitary issues. Annu. Rev. Phytopathol. 41:305-324.

35. Schneider, K. A., and Kelly, J. D. 2000. A greenhouse screening protocol for Fusarium root rot in bean. HortScience 35:1095-1098.

36. Schoch, C. L., Sung, G.-H., López-Giráldez, F., Townsend, J. P., Miadlikowska, J., Hofstetter, V., Robbertse, B., Matheny, P. B., Kauff, F., Wang, Z., Gueidan, C., Andrie, R. M., Trippe, K., Ciufetti, L. M., Wynns, A., Fraker, E., Hodkinson, B. P., Bonito, G., Yahr, R., Groenewald, J. Z., Arzanlou, M., de Hoog, G. S., Crous, P. W., Hewitt, D., Pfister, D. H., Peterson, K., Gryzenhout, M., Wingfield, M. J., Aptroot, A., Suh, S.-O., Blackwell, M., Hillis, D. H., Griffith, G. W., Castlebury, L. A., Rossman, A. Y., Lumbsch, H. T., Lücking, R., Büdel, B., Rauhut, A., Diederich, P., Ertz, D., Geiser, D. M., Hosaka, K., Inderbitzin, P., Kohlmeyer, J., Volkmann-Kohlmeyer, B., Mostert, L., O’Donnell, K., Sipman, H., Rogers, J. D., Shoemaker, R. A., Sugiyama, J., Summerbell, R. C., Untereiner, W., Johnston, P., Stenroos, S., Zuccaro, A., Dyer, P., Crittenden, P., Cole, M. S., Hansen, K., Trappe, J. M., Lutzoni, F., and Spatafora, J. W. 2009. The Ascomycota tree of life: A phylum wide phylogeny clarifies the origin and evolution of fundamental reproductive and ecological traits. Syst. Biol. 58:224-239.

37. Sicard, D., Michalakis, Y., Dron, M., and Neema, C. 1997. Genetic diversity and pathogenic variation of Colletotrichum lindemuthianum in the three centers of diversity of its host, Phaseolus vulgaris. Phytopathology 87:807-813.

38. Slippers, B., Stenlid, J., and Wingfield, M. J. 2005. Emerging pathogens: Fungal host jumps following anthropogenic introduction. Trends Ecol. Evol. 20:420-421.

39. Snyder, W. C., and Hansen, H. N. 1941. The species concept in Fusarium with reference to section Martiella. Amer. J. Bot. 28:738-742.

40. Suga, H., Hasegawa, T., Mitsui, H., Kageyama, K., and Hyakumachi, M. 2000. Phylogenetic analysis of the phytopathogenic fungus Fusarium solani based on the rDNA-ITS region. Mycol. Res. 104:1175-1183.

41. Suga, H., Ikeda, S., Taga, M., Kageyama, K., and Hyakumachi, M. 2002. Electrophoretic karyotyping and gene mapping of seven formae speciales in Fusarium solani. Curr. Genet. 41:254-260.

42. Swofford, D. L. 2002. PAUP*. Phylogenetic Analysis Using Parsimony (*and other methods), version 4.0b10. Sinauer Associates, Sunderland, MA.

43. Taylor, J. W., Jacobson, D. J., Kroken, S., Kasuga, T., Geiser, D. M., Hibbett, D. S., and Fisher, M. C. 2000. Phylogenetic species recognition and species concepts in Fungi. Fungal Genet. Biol. 31:21-32.

44. van der Does, H. C., Lievens, B., Claes, L., Houterman, P. M., Cornelissen, B. J. C., and Rep, M. 2008. The presence of a virulence locus discriminates Fusarium oxysporum isolates causing tomato wilt from other isolates. Environ. Microbiol. 10:1475-1485.

45. VanEtten, H. D., and Kistler, H. C. 1998. Nectria haematococca mating populations I and VI. Adv. Plant Pathol. 6:189-206.

46. Ward, T. J., Clear, R. M., Rooney, A. P., O’Donnell, K., Gaba, D., Patrick, S., Starkey, D. E., Gilbert, J., Geiser, D. M., and Nowicki, T. W. 2008. An adaptive evolutionary shift in Fusarium head blight pathogen populations is driving the rapid spread of more toxigenic Fusarium graminearum in North America. Fungal Genet. Biol. 45:473-484.

47. Yang, X. B., and Lundeen, P. 1997. Occurrence and distribution of soybean sudden death syndrome in Iowa. Plant Dis. 81:719-722.

48. Yli-Mattila, T., Gagkaeva, T., Ward, T. J., Aoki, T., Kistler, H. C., and O'Donnell, K. 2009. A novel Asian clade within the Fusarium graminearum species complex includes a newly discovered cereal head blight pathogen from the Russian Far East. Mycologia Published Online DOI: $10.3852 / 08-217$.

49. Zhang, N., O’Donnell, K., Sutton, D. A., Nalim, F. A., Summerbell, R. C., Padhye, A. A., and Geiser, D. M. 2006. Members of the Fusarium solani species complex that cause infections in both humans and plants are common in the environment. J. Clin. Microbiol. 44:2186-2190.

50. Zwickl, D. J. 2006. Genetic algorithm approaches for the phylogenetic analysis of large biological sequence data sets under the maximum likelihood criterion. Ph.D. dissert. The University of Texas, Austin. 